\title{
CAMA
}

Centre for Applied Macroeconomic Analysis

\section{Analyzing Credit Risk Transmission to the Non- Financial Sector in Europe: A Network Approach}

\section{CAMA Working Paper 43/2019 June 2019}

\section{Christian Gross}

European Systemic Risk Board (ESRB)

European Central Bank (ECB)

Department of Economics, University of Muenster, Germany

\section{Pierre L. Siklos}

Department of Economics, Wilfrid Laurier University

Balsillie School of International Affairs

Centre for Applied Macroeconomic Analysis, ANU

\section{Abstract}

We use a factor model and elastic net shrinkage to model a high-dimensional network of European CDS spreads. Our empirical approach allows us to assess the joint transmission of bank and sovereign risk to the non-financial corporate sector. Our findings identify a sectoral clustering in the CDS network, where financial institutions are in the center and non-financial entities as well as sovereigns are grouped around the financial center. The network has a geographical component reflected in different patterns of real-sector risk transmission across countries. Our framework also provides dynamic estimates of risk transmission, a useful tool for systemic risk monitoring. 


\section{Keywords}

networks, financial-real linkages, connectedness, systemic risk, credit risk, contagion, large datasets

\section{JEL Classification}

C32, C38, C55, F3, G01, G15

\section{Address for correspondence:}

(E) cama.admin@anu.edu.au

\section{ISSN 2206-0332}

The Centre for Applied Macroeconomic Analysis in the Crawford School of Public Policy has been established to build strong links between professional macroeconomists. It provides a forum for quality macroeconomic research and discussion of policy issues between academia, government and the private sector.

The Crawford School of Public Policy is the Australian National University's public policy school, serving and influencing Australia, Asia and the Pacific through advanced policy research, graduate and executive education, and policy impact. 


\title{
Analyzing Credit Risk Transmission to the Non-Financial Sector in Europe: A Network Approach*
}

\author{
Christian Gross ${ }^{\dagger}$ and Pierre Siklos ${ }^{\ddagger}$
}

May 31, 2019

\begin{abstract}
We use a factor model and elastic net shrinkage to model a high-dimensional network of European CDS spreads. Our empirical approach allows us to assess the joint transmission of bank and sovereign risk to the non-financial corporate sector. Our findings identify a sectoral clustering in the CDS network, where financial institutions are in the center and non-financial entities as well as sovereigns are grouped around the financial center. The network has a geographical component reflected in different patterns of real-sector risk transmission across countries. Our framework also provides dynamic estimates of risk transmission, a useful tool for systemic risk monitoring.
\end{abstract}

JEL Classification: C32, C38, C55, F3, G01, G15

Keywords: networks, financial-real linkages, connectedness, systemic risk, credit risk, contagion, large datasets

* Large parts of the research project were conducted while Christian Gross was affiliated with the University of Muenster (Germany) and while he was a visiting researcher at the Balsillie School of International Affairs in Waterloo, Canada. The research visit was financed through a research grant provided by the "Teilfonds Nachwuchsförderung" of the Department of Business and Economics, University of Muenster. We thank Martin Bohl, Nicole Branger, Pierre Collin-Dufresne, Sören Gröbel, Magdalena Grothe, Thomas Kick, Tuomas Peltonen, Isabel Schnabel, Volker Wieland, Serhat Yildiz (discussant), two anonymous referees and seminar participants at the Deutsche Bundesbank and the University of Muenster for helpful comments and suggestions. We are also grateful for input from participants at the 11th International Conference on Computational and Financial Econometrics (CFE 2017) in London, the SFA Annual Conference 2018 in Asheville, the Econometric Society European Winter meeting 2018 in Naples and the 27th Annual Symposium of the Society for Nonlinear Dynamics and Econometrics at the Dallas Fed. Lasse Laumann provided able research assistance. The views expressed in this paper are those of the authors and not necessarily those of the European Systemic Risk Board or the European Central Bank.

${ }^{\dagger}$ Corresponding author: European Systemic Risk Board (ESRB), European Central Bank (ECB) \& Department of Economics, University of Muenster, Germany; Sonnemannstrasse 20, Frankfurt am Main, Germany, phone: +49 691344 8526, email: christian.gross@ecb.europa.eu

${ }_{\ddagger}^{\ddagger}$ Department of Economics, Wilfrid Laurier University, Balsillie School of International Affairs and Centre for Applied Macroeconomic Analysis (CAMA) 


\section{Introduction}

As a consequence of the European sovereign debt crisis that followed the 2007-08 financial crisis, the sovereign-bank nexus attracted considerable attention in the literature (e.g., Acharya et al. 2014; Alter and Beyer 2014; De Bruyckere et al. 2013). In contrast, little empirical evidence exists on the degree to which the non-financial corporate sector (real sector) in Europe has been affected by the rise in sovereign and bank credit risk. There are two empirical studies that investigate the impact of sovereign credit risk on the non-financial corporate sector based on European credit default swap (CDS) data (Bedendo and Colla 2015; Augustin et al. 2018). Both studies find significant risk spillovers from sovereigns to corporations in Europe. However, there is only scant evidence on the transmission of credit risk from financial institutions to non-financial corporations during the crisis events. In addition, little attention has been paid to the simultaneous measurement of interactions between all three sectors of the economy (financial, sovereign, and non-financial). Given that a fundamental component in the concept of systemic risk is the notion of negative externalities for the real economy, ${ }^{1}$ incorporating these negative real effects in any quantitative measurement of systemic risk should be given greater emphasis.

In order to fill this gap in the literature, this paper conducts a network analysis that captures the linkages among 152 CDS series for European sovereigns, financial institutions and non-financial corporations over the period 2006-2017. Our unified empirical framework incorporates recent techniques to measure systemic risk by quantifying connectedness in highdimensional networks, similar to the approaches adopted by Barigozzi and Hallin (2017) and Demirer et al. (2018). Specifically, we employ elastic net shrinkage in a vector autoregressive (VAR) setup to overcome the dimensionality problem in large datasets. We also control for common shocks using a dynamic factor approach. We derive static and dynamic measures

\footnotetext{
${ }^{1}$ Following the report prepared by the International Monetary Fund (IMF), the Financial Stability Board (FSB) and the Bank for International Settlements (BIS) for the G20, systemic risk can be defined as "a risk of disruption to financial services that is (i) caused by an impairment of all or parts of the financial system and (ii) has the potential to have serious negative consequences for the real economy"(IMF/FSB/BIS 2009, p. 2).
} 
of connectedness to characterize the network of CDS spreads over the sample period. The empirical evidence presented in this paper contributes to a better understanding of the financial and real economic effects of the crisis events in the past decade. To the best of our knowledge, we are the first to provide evidence on the joint transmission of bank and sovereign risk to the European non-financial sector.

Our empirical approach has close ties to recent theoretical work that emphasizes network connectedness in financial or economic contexts. For example, there is a growing body of theoretical studies that illustrate how increasing interconnectedness can pose a serious threat to the stability of the financial system due to contagion and amplification effects (Acemoglu et al. 2015; Elliott et al. 2014; Glasserman and Young 2015; Glasserman and Young 2016). From a real-sector perspective, Acemoglu et al. (2012) show that intersectoral input-output linkages between firms can give rise to aggregate (or economy-wide) fluctuations when idiosyncratic or sectoral shocks propagate, thus leading to network effects that impact the aggregate economy.

The adverse interactions between banks, corporates and sovereigns played a prominent role in the Eurozone crisis (IMF 2013). One transmission channel making corporations vulnerable to changes in sovereign creditworthiness is the so-called "transfer-risk" channel. It implies that distressed governments may be forced to shift some parts of the debt burden to the corporate sector; for example, by raising corporate taxes. An increase in sovereign risk may therefore lead to lower current and future profitability in the corporate sector (Acharya et al. 2014). Another reason to expect a sovereign-corporate link is the joint influence of rating agencies. Borensztein et al. (2013) provide evidence for "sovereign ceilings" that prevent corporations from being rated above the sovereign. Deteriorations in credit ratings of sovereigns thus lead to lower ratings for corporations located in the respective country, translating into higher costs of debt capital for the corporate sector (Almeida et al. 2017).

Besides the sovereign-corporate link, there are reasons to assume a relationship between banks and the non-financial corporate sector. Since banks in financial distress need to 
reduce their credit exposure and/or increase interest rates, corporations are likely to face higher bank funding costs. This can erode the financial health of these firms and increase the probability of default. Abildgren et al. (2013) provide evidence for such a relationship based on micro data for banks and firms in Denmark. Minamihashi (2011) identifies a credit crunch effect resulting from bank failures in Japan, which leads to a substantial decrease in the investment activity of client firms.

There is, of course, a very large literature that deals with the transmission of financial risks of various kinds that cannot be reviewed due to space limitations. Moreover, a rich variety of channels exist that explain the propagation of financial risks both across types of financial assets as well as across countries. A considerable portion of the literature has focused on generating empirical results. Betz et al. (2016) investigate the network for the sovereign-bank nexus in Europe. They find that, during the Eurozone sovereign debt crisis, financial markets fragmented along national borders. Moreover, connectedness is found to peak around 2008-10 and again around 2011-13 which is compatible with our findings. An important difference between their study and ours, however, is that we explicitly evaluate the transmission of risks beyond the banking sector, using a sample of CDS spreads that includes a large number of non-financial corporations. For a comprehensive review on risk spillovers we refer the reader to two related literature surveys by Hasman (2013) and Chinazzi and Fagiolo (2013). One feature of the literature is that there is still an overwhelming emphasis on the transmission of risks between banks and sovereigns. ${ }^{2}$ Augustin et. al. (2018) and Bedendo and Colla (2015) are exceptions. Nevertheless, in common with our study and the literature more generally, there is also a preference to relying on CDS spreads (e.g., Acharya et al. 2014; Bedendo and Colla 2015; Betz et al. 2016; Breckenfelder and Schwaab 2018).

Our goal is to quantify the joint transmission of bank and sovereign credit risk to the nonfinancial corporate sector in Europe by making use of recent advances in the econometrics of

\footnotetext{
${ }^{2}$ Also notable according to the surveys cited above is that theoretical models have yet to catch-up in explaining the extant empirical evidence about how and why connectivity between financial assets evolves in the manner reported by several studies.
} 
large-dimensional networks. We estimate and visualize our corporate-financial-sovereign network both statically (full-sample period) and dynamically (rolling-window). For the static case we find that our network is characterized by a dominant financial sector located in the center of the network, while non-financial corporations and sovereigns are grouped in sectoral clusters around the financial center. Aggregating contagion effects to the non-financial sector at the country-level reveals a strong geographical component in the network, reflected in sizeable differences in the pattern of real-sector risk transmission between peripheral countries and countries located in the geographical center of Europe. Based on the dynamic estimation framework we identify an increase in the transmission of financial and sovereign credit risk to the non-financial sector during the global financial crisis and the European debt crisis. By contrast, we find that the transmission of risk within the non-financial sector remained largely unchanged during crisis events. We conclude that financial and sovereign risk were main drivers of European corporate credit risk in the period considered.

Viewed in isolation some of our findings are not surprising. After all, the onset and spread of the financial crisis in Europe clearly possessed a strong geographic element even if some countries felt the impact more strongly than others. However, we demonstrate that there is significant time variation in both the cross-sectoral transmission of risk and in the degree of system-wide risk transmission. This yields new insights into how the nexus of credit risk between banks, sovereigns and non-financial firms evolved over time. To our knowledge we are the first to generate such results within a unified empirical framework. Moreover, our framework is a useful tool for policy institutions as it allows for a quasi real-time monitoring of systemic risks in the financial sector and beyond.

The remainder of this paper is organized as follows. Section 2 outlines the econometric methodology for estimating and visualizing the networks. Section 3 describes the data used in our analysis. In Section 4 we present and discuss our results. Finally, we provide a brief conclusion and an outlook in Section 5. 


\section{Econometric methodology}

We use variance decompositions in VAR models to assess the interconnectedness of CDS returns. Diebold and Yilmaz (2014) show that the classical VAR framework can be used to model the network structure for a panel of time series by defining the weight associated with edge $(i, j)$ in the network as the proportion of the $h$-step-ahead forecast error variance of variable $i$ that is accounted for by the innovations in variable $j$. While this methodology is in principle applicable to a wide range of different settings, it is constrained by curse-ofdimensionality problems, as classical VAR estimation becomes unstable in high-dimensional networks. Demirer et al. (2018) tackle the dimensionality problem of the Diebold-Yilmaz approach by estimating the network using the LASSO ("least absolute shrinkage and selection operator"), a penalized regression method that allows to select and shrink the VAR parameters in optimal ways. Barigozzi and Hallin (2017) propose to remove the effect of common shocks before applying LASSO or related penalized regression techniques, as the presence of collinearity badly affects estimation stability.

Following these recent developments in the econometric modelling of networks, we apply a 'factor plus sparse VAR' approach in our analysis of credit risk transmission. That is, we first implement a factor model to remove common shocks and then, using the idiosyncratic returns, estimate a large-dimensional VAR that considers elastic net shrinkage, a variant of LASSO methods, to tackle dimensionality issues. Given the large number of time series under investigation in our study it becomes imperative to find ways of adapting the DieboldYilmaz approach, now widely used in the literature, but combine their methodology with tests that provide the means to economize on the considerable demands on the data.

Other approaches using shrinkage methods such as LASSO to characterize financial networks may be found in the literature. One example is the study by Betz et al. (2016) which constructs generalized tail-risk networks for the European bank-sovereign system. In their approach the network link between entities $i$ and $j$ is defined by their degree of tail dependence using LASSO quantile regressions, i.e. how much a change in $j$ 's conditional 
Value-at-Risk (VaR) impacts the VaR of $i$. Our approach instead relies on quantifying connectedness based on mean estimates of variance decompositions and using elastic net for shrinking and selecting the parameters. In addition, while Betz et al. (2016) use observable variables (macro-financial state variables) to control for common shocks, our framework considers a latent factor structure.

\subsection{Removing common shocks}

Similar to Barigozzi and Hallin (2017), we use dynamic factor methods to separate common shocks from idiosyncratic shocks before estimating the network structure. For our $n \times T$ panel of logarithmic CDS returns $\boldsymbol{Y}=\left(Y_{1 t}, Y_{2 t}, \ldots, Y_{n t}\right)^{\prime}$, we consider the generalized dynamic factor model representation by Forni et al. (2000, 2015, 2017) and Forni and Lippi (2001), which admits the decomposition of $\boldsymbol{Y}:=Y_{i t}$, for all $i$ and $t$, into a common component $X_{i t}$ and an idiosyncratic component $Z_{i t}$ :

$$
Y_{i t}=X_{i t}+Z_{i t}
$$

It is further assumed that the common component is driven by $q$ factors defined as an orthonormal unobservable white noise vector $\boldsymbol{u}_{t}=\left(u_{1 t}, u_{2 t}, \ldots, u_{q t}\right)^{\prime}$, such that $X_{i t}$ can be expressed as an auto-regressive representation $X_{i t}=\sum_{k=1}^{q} b_{i k}(L) u_{k t}$, where the filters $b_{i k}(L)$ are one-sided and square summable. Using frequency-domain principal components (Brillinger 1981), Forni et al. $(2015,2017)$ show how to recover the common and idiosyncratic components based on an estimator for the spectral density of $X_{n t}$.

To determine the number of factors $q$, we apply the Hallin and Liška (2007) criterion, which favors $q=1 .^{3}$ Consequently, we choose to conduct our analysis with one common factor. ${ }^{4}$ Figure 1 shows the evolution of the common factor over the sample period. Most

\footnotetext{
${ }^{3}$ The Online Appendix provides a detailed discussion of the methodology to determine the number of common factors in the sample.

${ }^{4}$ This is in line with Berndt and Obreja (2010) who show for the period 1994-2008 that the common dynamics in European CDS spreads are captured by a single common factor (first principal component) which accounts for about half of the variation in their sample, while the second factor (second principal component) explains only 8 percent.
} 
notable are the clusters of large CDS spread changes during the 2007-09 global financial crisis and the 2010-12 European sovereign debt crisis, reflecting the highly volatile financial markets during these periods.

\section{[FiguRE 1 about here]}

To provide a more detailed characterization of the common factor, we report some statistics regarding its properties in Table 1. Panel A shows the proportion of variance explained by the common factor averaged by sectors and over the total sample, respectively. In total, the common factor explains about one third of the variation in all CDS returns and between 44 and 46 percent of the variation in corporate sector CDS. For the sovereign sector average explanatory power is considerably lower (9 percent). To give an indication of the fundamental drivers of the common factor, we investigate in Panel B the correlation of the common factor with the CBOE Volatility Index (VIX), a measure of global uncertainty and risk aversion, and a key determinant of the global financial cycle (Rey 2015). We find a clear positive relationship between the common factor of European CDS returns and the VIX, indicating that European CDS spreads increase when global uncertainty increases.

[TABLE 1 about here]

From a conceptual perspective, a key motivation underlying our approach of disentangling idiosyncratic from common drivers of variation in our dataset of CDS returns is that we are interested in measuring the "pure" contagion risk component of systemic risk. Contagion risk can be defined as "an initially idiosyncratic problem that becomes more widespread in the cross-section, often in a sequential fashion" (ECB 2011, p. 141). Our empirical framework thus separates contagion risk from a second form of systemic risk: the common exposure to shocks in financial markets or the macroeconomy (De Bandt et al. 2009; ECB 2011). Moreover, by focusing on idiosyncratic dependencies of CDS returns, our empirical strategy is closer to the theoretical concept of financial networks in which the origin of contagion is 
a shock to an individual institution that is subsequently transmitted to other institutions through the web of obligations (Glasserman and Young 2016). ${ }^{5}$

An alternative framework to the latent factor model employed in this paper is to use a structural model approach in which credit spreads are determined by a number of structural factors suggested by theory such as interest rates, leverage and asset volatility (CollinDufresne and Goldstein 2001; Leland and Toft 1996; Longstaff and Schwartz 1995). Structural models are widely used in credit risk modelling; yet empirical tests suggest that structural models typically cannot accurately explain credit spreads (Eom et al. 2004; Huang and Zhou 2008). ${ }^{6}$ Relatedly, the empirical literature finds that changes in credit spreads are even harder to explain by structural factors than levels (Collin-Dufresne et al. 2001; Zhang et al. 2009). Hence, while structural models provide important insights on underlying theoretical pricing mechanisms, we employ a more practical reduced-form approach to explain interdependencies between CDS spreads, while remaining silent on the economic (structural) determinants of spreads.

\subsection{Characterizing networks via variance decompositions}

To obtain empirical measures that help to characterize the network of CDS returns, we build on the econometric framework proposed by Diebold and Yilmaz (2014) and Demirer et al. (2018), which is based on variance decompositions in large-dimensional VAR models. ${ }^{7}$

Specifically, we write the following covariance stationary VAR with $n$ endogenous variables, representing the $n$ estimated idiosyncratic components $Z_{t}=\left(Z_{1 t}, Z_{2 t}, \ldots, Z_{n t}\right)^{\prime}$ as defined in

\footnotetext{
${ }^{5}$ An alternative approach to control for common shocks is to include observable market variables as exogenous regressors in the econometric model. However, the drawback of this strategy is that these relevant market variables need to be identified a priori by the researcher with the consequence that the results might be dependent upon the particular set of chosen market variables.

${ }^{6}$ Eom et al. (2004) analyse five different structural models empirically and conclude that the accuracy of structural models is a problem. They find that most structural models overestimate the credit spread of riskier firms and underestimate the credit risk of safer firms. Similarly, Huang and Zhou (2008) test five structural models for empirical accuracy and reject three of the models. However, the other two models still fail to predict CDS spreads accurately.

${ }^{7}$ An earlier but less general version of this methodology is outlined in Diebold and Yilmaz $(2009,2012)$.
} 
Eq. (1):

$$
Z_{t}=\sum_{k=1}^{p} \Phi_{k} Z_{t-k}+\varepsilon_{t}
$$

where $\varepsilon_{t} \sim\left(0, \sum\right), \Phi_{k}$ is a parameter matrix of dimension $n \times n$ and the lag length is two $(p=2)$.

The model in Eq. (2) can be expressed in its moving average representation as follows:

$$
Z_{t}=\sum_{k=0}^{\infty} A_{k} \varepsilon_{t-k},
$$

where $A_{k}$ is the matrix of moving average coefficients at lag $k$. These moving average coefficients are crucial for assessing the dynamics of the system. Using forecast error variance decompositions for $h$ steps ahead enables to determine how much of the variance of each variable $Z_{i}$, for $i=1,2, \ldots, n$, is due to shocks to another variable included in the system. In calculating variance decompositions we adopt the generalized impulse-response framework of Koop et al. (1996) and Pesaran and Shin (1998), using a forecast horizon of $h=10$ days. ${ }^{8}$ This approach accounts for correlated shocks across markets by using the historically observed distribution of the shocks. As a consequence, all estimation results are invariant to the ordering of variables in the VAR. The invariance to ordering can also be seen as a disadvantage as it circumvents a direct role for economic theory in providing guidance about the ordering of the variables. While a sensible approach might be to rank variables from, say, most to least systemically important this is very challenging when there are 152 variables to consider. Moreover, history also suggests that it need not always be the most systemically important country or firm that triggers a crisis (i.e., the so-called 'black swan'). If that is the case any ordering of the VAR is likely to be viewed as being arbitrary.

Defining $\theta_{i j}$ as the $h$-step-ahead error variance in forecasting variable $Z_{i}$ that is due to shocks to variable $Z_{j}$, where $i, j=1,2, \ldots n$, we can obtain the relative contribution (in percent) of each variable $Z_{j}$ to the forecast error of variable $Z_{i}$ by normalizing by the sum

\footnotetext{
${ }^{8}$ The results are robust to changing the forecast horizon (see robustness checks in Section 4.3.3).
} 
of all row entries in the variance decomposition matrix:

$$
\gamma_{i j}=\frac{\theta_{i j}}{\sum_{j=1}^{n} \theta_{i j}} \times 100
$$

Each element $\gamma_{i j}$ has a value between 0 and 100 and provides a quantitative measure for the pairwise directional connectedness from CDS entity $j$ to CDS entity $i$. Based on the estimates for pairwise directional connectedness, it is possible to construct a range of informative connectedness measures by summing the elements $\gamma_{i j}$ at different levels of aggregation, from individual (firm- or sovereign-level) to aggregate connectedness (system-wide).

At the individual level, total directional connectedness to entity $i$ "from" all other entities $j$ is defined as:

$$
\gamma_{i \leftarrow \bullet}=\frac{\sum_{j=1 j \neq i}^{n} \gamma_{i j}}{\sum_{i, j=1}^{n} \gamma_{i j}}=\frac{\sum_{j=1 j \neq i}^{n} \gamma_{i j}}{n} .
$$

Conversely, total directional connectedness from entity $i$ "to" all other entities $j$ can be constructed as follows:

$$
\gamma_{\bullet \leftarrow i}=\frac{\sum_{j=1 j \neq i}^{n} \gamma_{j i}}{\sum_{i, j=1}^{n} \gamma_{j i}}=\frac{\sum_{j=1 j \neq i}^{n} \gamma_{j i}}{n} .
$$

Note that the individual measures can also be restricted to a subset of entities $j$. For example, we will be interested in the total directional connectedness from (to) entity $i$ to (from) all sovereign/financial/non-financial entities $j$.

The most aggregate measure of connectedness (system-wide connectedness) is obtained by summing all individual measures of total directional connectedness:

$$
\gamma^{\text {Total }}=\frac{\sum_{i, j=1 i \neq j}^{n} \gamma_{i j}}{\sum_{i, j=1}^{n} \gamma_{i j}}=\frac{\sum_{i, j=1 i \neq j}^{n} \gamma_{i j}}{n} .
$$

Moreover, we can construct additional aggregate measures such as sectoral connectedness by aggregating pairwise connectedness measures at the sector-level and geographical connectedness by aggregating pairwise connectedness at the country-level. We use several indicators in order to provide a comprehensive overview of the composition of connectedness. 


\section{$2.3 \quad$ Elastic net shrinkage}

Since our VAR needs to be estimated in very high dimensions (152 variables), it is essential to reduce the number of parameters to be estimated in order to circumvent the "curse of dimensionality". In our network analysis we use elastic net shrinkage (Zou and Hastie 2005), which is a variant of LASSO methods, to shrink, select and estimate our VAR model. ${ }^{9}$ While there are few comparisons of the properties of different forms of LASSO shrinkage (these are more common in the medical literature) the elastic net penalty has the advantage of being relatively less aggressive in reducing the number of selected variables. It also tends to group predictors that are more strongly correlated. Hence, the likelihood of incorrectly omitting a variable is reduced. Simulation studies and real world applications show that the elastic net estimator often outperforms the pure LASSO, particularly when the number of predictors is large relative to the number of observations (Zou and Hastie 2005). Consequently, the benefits of the elastic net estimator materialize especially well in our dynamic (rolling-window) estimation of the CDS network as here the sample size becomes small but the number of variables remains large.

Elastic net solves the following least-square estimation problem:

$$
\widehat{\beta}=\underset{\beta}{\operatorname{argmin}}\left(\sum_{t=1}^{T}\left(Z_{i t}-\sum_{k=1}^{p} \boldsymbol{\beta}_{\boldsymbol{k}, \boldsymbol{i}}^{\prime} \boldsymbol{Z}_{\boldsymbol{t}-\boldsymbol{k}}\right)^{2}+\lambda \sum_{k=1}^{p}\left[(1-\alpha)\left|\boldsymbol{\beta}_{\boldsymbol{k}, \boldsymbol{i}}\right|+\alpha\left|\boldsymbol{\beta}_{\boldsymbol{k}, \boldsymbol{i}}\right|^{2}\right]\right),
$$

where $i=1, \ldots, n$, and $\boldsymbol{Z}$ is the matrix of idiosyncratic returns. Zou and Hastie (2005) define the function $(1-\alpha)\left|\boldsymbol{\beta}_{\boldsymbol{k}, \boldsymbol{i}}\right|+\alpha\left|\boldsymbol{\beta}_{\boldsymbol{k}, \boldsymbol{i}}\right|^{2}$ as the elastic net penalty, which is a combination of the "LASSO penalty" and the "ridge penalty". The elastic net penalty is controlled by $\alpha$ that takes a value between 0 and 1. For $\alpha=1$, the elastic net becomes simple ridge regression, and for $\alpha=0$, we obtain the LASSO penalty. The tuning parameter $\lambda$ controls the overall strength of the penalty with the number of penalized (zero) regressors increasing in $\lambda$. Hence, for $\lambda=0$ we obtain the standard OLS estimator with no penalization and no selection. We

\footnotetext{
${ }^{9}$ See Tibshirani (1996) for an introduction to LASSO.
} 
select $\alpha$ and $\lambda$ jointly for each equation by 10 -fold cross validation over a grid of possible values, using the values for $\alpha$ and $\lambda$ that produce the lowest in-sample mean squared error for the model. While selecting both $\alpha$ and $\lambda$ by cross validation is computationally very costly, particularly when it comes to rolling-window regressions where the procedure is repeated for each window, this approach ensures that we pick the set of regressors with the best in-sample model fit. By contrast, fixing $\alpha$ and choosing only $\lambda$ would be computationally less costly, but would result in a worse in-sample model fit as shown by our out-of sample forecast exercise reported in Section 4.3.1.

\subsection{Network visualization}

Due to the high-dimensional nature of our network, consisting of 152 nodes and $152 \times 151=$ 22, 952 links, presenting the results in an informative manner is challenging. In what follows, we characterize the estimated networks by means of graphical representations that visualize the results according to data characteristics and estimated connectedness measures. ${ }^{10}$

Node names and colors: Each node represents one variable abbreviated by a three-digit name code (see Table A.1 in the Appendix for a detailed list of all name codes). Node color is defined by the sectoral affiliation of each entity: Financial Institutions are yellow, Sovereigns are red, Autos \& Industrials are blue, Consumers are green, Energy corporations are purple, and TMT (Technology, Media \& Telecommunications) firms are light salmon.

Node size: Node size is a linear function of total directional connectedness "to others" (Eq. 6). Hence, entities that contribute relatively more credit risk to other entities are represented by bigger nodes in the network. Node size can be interpreted as a direct visual measure of systemic importance of the respective firm or sovereign.

Node location: We use the force-directed algorithm of Fruchterman and Reingold (1991) to determine node location. The algorithm positions the nodes in the two-dimensional space in such a way that repelling and attracting forces among the nodes exactly balance. The

\footnotetext{
${ }^{10}$ All network visualizations are generated in the software $\mathrm{R}$ using the packages igraph and ggplot2.
} 
force of repulsion and attraction between two nodes is determined by pairwise directional connectedness "to" and "from". CDS entities that are linked through high pairwise directional connectedness are thus positioned close to each other, while CDS entities that are linked through low pairwise directional connectedness are drawn further apart. As a result, CDS entities with many strong links to other entities will be located in the network's center (i.e., these entities are more systemically important), while nodes for CDS entities with weak links to others will be located in the network's periphery (less systemically important).

Link thickness: Each link is a linear function of pairwise directional connectedness such that a relatively thicker link between two nodes indicates strong pairwise connectedness.

\section{Data}

Our data set comprises 152 daily CDS series of European sovereigns, financial institutions, and non-financial corporations. CDS spreads provide a more accurate measure of credit risk (i.e., the risk of an entity defaulting on its debt) than bond yields for three main reasons. First, CDS contracts are standardized products with pre-specified and fully documented credit derivatives agreements (Augustin et al. 2014), whereas bond terms and conditions are heterogeneous and depend on various features, including maturity, issue amount and coupon structure. Second, CDS markets are typically less influenced by liquidity effects relative to bond markets. Longstaff et al. (2005), for example, find that a large proportion of bond spreads is related to measures of bond-specific illiquidity such as bid-ask differentials. ${ }^{11}$ Third, CDS spreads provide a timelier market-based indicator of credit risk, as documented by empirical studies showing that CDS markets lead bond markets in the price discovery process (Blanco et al. 2005; Palladini and Portes 2011).

We consider CDS spreads with a maturity of five years, which is typically the contract

\footnotetext{
${ }^{11}$ While recent theoretical and empirical evidence suggests that CDS prices are influenced by liquidity effects too (Bongaerts et al. 2011; Corò et al. 2013), the magnitude of these effects is likely to be greater for bond markets than for CDS markets. Comparing the magnitude of the liquidity premium across CDS and bond markets, Bühler and Trapp (2009) estimate that 35 percent of bond spreads is attributable to liquidity, whereas in CDS markets the liquidity component is only 4 percent.
} 
specification with the highest liquidity. We choose CDS quotes for euro-denominated senior unsecured debt with the modified-modified restructuring clause for firms and the cumulative restructuring clause for sovereigns. These types of contracts represent the conventional terms for CDS contracts in Europe. The sample period runs from October 23, 2006 to July 28, 2017, thus covering both the global financial crisis and the European sovereign debt crisis. ${ }^{12}$ We source our data through Datastream and Bloomberg. ${ }^{13}$

Our sample includes sovereign CDS quotes from the following 10 countries: Austria, Belgium, France, Germany, Ireland, Italy, Netherlands, Portugal, Spain and the UK. ${ }^{14}$ To ensure that our sample comprises the most relevant European corporate CDS entities, we consider only data from financial and non-financial corporations that were part of the Markit iTraxx Europe index over the sample period. ${ }^{15}$ The Markit iTraxx Europe refers to the 125 most actively traded European corporate entities with investment grade credit ratings. The index contains corporate CDS from five different sectors: Autos \& Industrials, Consumers, Energy, TMT (Technology, Media \& Telecommunications) and Financials. The group of financial CDS entities includes both banks and non-bank financial intermediaries (insurance companies). Our analysis thus addresses the need expressed by regulators to include insurance companies in systemic risk assessments. ${ }^{16}$

\footnotetext{
${ }^{12}$ The starting date of our sample is dictated by data availability. Using an earlier starting date would result in a substantially smaller sample of CDS series due to missing data.

${ }^{13}$ Our procedure in collecting the data is as follows: we first check data availability for a specific CDS entity in Datastream; if the data are available, we include them in our sample; if the data are not available in Datastream, we check data availability in Bloomberg and add the series to our sample if the data are available.

${ }^{14}$ Data for Greece are not available for the full-sample period, because trading of Greek CDS contracts was suspended from March 9, 2012, when a so-called "credit event" was declared by the International Swaps and Derivatives Association as a consequence of the Greek debt restructuring agreement. We therefore omit Greek CDS from our analysis.

${ }^{15}$ The constituents of the iTraxx Europe are revised twice a year, such that there are frequent changes in the composition of the index. We decide to consider a company for inclusion in our sample if it was at least once part of the iTraxx Europe index during our sample period.

${ }^{16}$ Insurance companies can be important for financial stability because they are major investors in financial markets, insurers and banks are increasingly interconnected and insurance companies insure the (financial) risks of households and firms (ECB 2009). G20 governments reacted to the growing importance of insurers for financial stability by asking the Basel Financial Stability Board (FSB) to consider insurers alongside banks in the development of a policy framework to specifically address the systemic risks associated with systemically important financial institutions (FSB 2011).
} 
After excluding all corporate CDS series for which more than 15 percent of the observations are stale values, our final sample consists of CDS spreads for 109 non-financial corporations, 33 financial institutions, and 10 sovereigns. Table A.1 provides a full list of all companies and countries included in our analysis and Table OA.1 in the Online Appendix reports summary statistics (by country).

\section{Empirical results}

We characterize the CDS network both statically (full-sample) and dynamically (rollingwindow) based on variance decompositions of the idiosyncratic CDS returns in a largedimensional VAR. Providing time-varying estimates for contagion effects to the non-financial sector is one of the principal contributions of this study as this is essential for generating useful policy implications.

\subsection{Static estimation of the CDS network}

\subsubsection{Full-sample individual CDS network}

Figure 2 shows the full-sample CDS network using the force-directed algorithm by Fruchterman and Reingold (1991) to determine node locations. We observe a strong sectoral clustering of corporates and sovereigns, as nodes of CDS entities from the same sector tend to bunch together. Financial institutions are all located in the center of the network, whereas nonfinancials and sovereigns are located around the center, indicating the systemic importance of the financial sector in Europe. The central role of the financial sector is also evidenced by the large node size of financial institutions relative to non-financial corporations and sovereigns. ${ }^{17}$ Non-financial companies in the sectors Consumers, Autos \& Industrials and TMT show the strongest links to the financial sector, while Energy corporations are located closer to the sovereign sector.

\footnotetext{
${ }^{17}$ As explained above, node size is a function of "to" connectedness. Hence, entities that are more important to the system in terms of credit risk transmission have larger nodes.
} 
[FIGURE 2 about here]

To provide a more detailed account of the most important individual transmitters of sovereign and bank credit risk to the non-financial sector, we present a ranking of the largest senders of credit risk in Table 2. The ranking is based on aggregating all pairwise directional connectedness measures "to" non-financial corporations for each individual financial institution and sovereign, respectively. The ranking can be interpreted as a quantitative indicator for the systemic importance of each financial and sovereign entity to the real economy. Conversely, we also present a ranking for the largest receivers of credit risk from sovereigns and financials in Table 2. It is shown that the ranking for the senders of financial risk is headed by two major European banks, namely Santander and Crédit Agricole, followed by a major insurance company (Swiss RE). All banks in the top 10 ranking (Santander, Crédit Agricole, Société Générale, BBVA and Unicredit) are designated by the FSB as "global systemically important banks" that are subject to additional capital and other regulatory requirements under the Basel III framework (see FSB (2014) for a complete list of all identified banks). ${ }^{18}$ The presence of five insurance companies in the top 10 of financial risk senders underscores the importance of including non-bank financial intermediaries into systemic risk assessments as proposed by regulators (ECB 2009).

[TABLE 2 about here]

An interesting feature of the financial institutions in our network is that their link size to non-financial firms is positively correlated with their link size to other financial institutions. Figure 3 depicts this relationship by plotting average directional connectedness of individual financial institutions to all non-financial firms (this corresponds to the observations in the ranking of senders in Table 2(a)) on the horizontal axis against average directional connectedness of individual financials to all other financial institutions on the vertical axis. The

\footnotetext{
${ }^{18} \mathrm{In}$ addition, the insurance company Allianz (rank 9 in Table 2) is designated as a "global systemically important insurer (G-SII)" by the FSB (see FSB (2016) for the separate list of all G-SIIs).
} 
structure of the estimated network hence reveals that financial institutions which generate the largest contagion effects within the financial system are also the most important transmitters of contagion effects to the real economy.

\section{[FIGURE 3 about here]}

Turning to the largest non-financial receivers of contagion effects from financial institutions (second panel in Table 2(a)), we observe that the top 10 is dominated by corporations from the sectors Autos \& Industrials (Air Liquide, Bayer, Akzo Nobel, Svenska Cellulosa) and Consumers (Henkel, Ahold Delhaize, Carrefour, Accor, Casino Guichard). A look at the bottom of the ranking indicates that energy corporations, such as RWE, BP and Iberdrola, are less affected by financial risk shocks.

As for the links between sovereigns and the non-financial sector (Table 2(b)), we find that the southern European countries Italy, Portugal and Spain, which were among the most severely stressed countries during the debt crisis, are by far the largest transmitters of credit risk. Sovereigns from the "core" of the Eurozone (Austria, Germany, France, Belgium, Netherlands) as well as the UK are much less important in terms of credit risk transmission. ${ }^{19}$ Finally, on the receiving end of the sovereign risk channel (second panel in Table 2(b)), we see that there are mainly energy companies at the top of the ranking. The only exceptions are the TMT companies Telefonica and Hellenic Telecom.

\subsubsection{Cross-sectoral network connectedness}

Building on the findings from the individual CDS network, which already highlighted some sectoral patterns in credit risk transmission, we next move to an aggregate perspective on cross-sectoral connectedness. Our aim is to identify sectoral heterogeneity in the magnitude of contagion effects. Figure 4 shows the sectoral decomposition of directional connectedness

\footnotetext{
${ }^{19}$ Surprisingly, Ireland is the least important sender despite its central role in the Eurozone crisis. This may be explained by Ireland's fast recovery from the crisis in comparison with the countries from southern Europe.
} 
from financials and sovereigns to non-financial firms. We observe that the financial sector is a more important contributor of credit risk to the non-financial sector than the sovereign sector. For the non-financial sectors Autos \& Industrials, Consumers and TMT the magnitude of contagion shocks from financial institutions is roughly two to four times stronger relative to sovereigns. Only energy companies are comparatively more affected by contagion shocks from sovereigns (by a factor of roughly 1.5). At the same time, compared with other nonfinancial sectors, the energy sector is less affected by contagion from financial institutions.

\section{[FiguRE 4 about here]}

An important factor that can explain both the relatively stronger sensitivity of the energy sector to sovereign risk shocks and the lower sensitivity to financial risk shocks is the ownership structure of energy corporations. The energy sector is of great strategic importance to the public sector, which is why sovereigns are often major shareholders in energy firms to retain influence on corporate decisions. ${ }^{20}$ Firms with government ties often receive stateguaranteed loans and are more likely to be bailed out than firms without government ties (Faccio et al. 2006). Our results are consistent with the notion that the energy sector's large proportion of (partially) government-controlled firms, and the superior financing conditions associated with government control, is responsible for the relatively lower exposure of the energy sector to financial risk shocks. At the same time, the prevailing degree of government control in the energy sector creates a stronger link to variations in sovereign risk, as rising concerns about the solvency of sovereigns erodes the credibility of state-guaranteed loans and decreases the likelihood for bailouts.

\footnotetext{
${ }^{20}$ Among the 18 energy firms in our sample, 9 are characterized by a substantial public ownership, i.e., the government share in the company is more than 5 percent based on publicly available sources (corporate websites, annual reports, etc.). By contrast, among the remaining non-energy firms in the non-financial sector only 12 percent are characterized by a substantial public ownership.
} 


\subsubsection{Geographical network connectedness}

Despite the common market there exist regional differences across European countries, ranging from cultural differences (including language) to purely economic differences related to e.g., macroeconomic fundamentals, credit ratings and the size of national banking sectors. All of these country-specific factors may give rise to a relationship between the geographical location of firms and sovereigns and the size/direction of credit risk transmission. ${ }^{21}$

\section{[FIGURE 5 about here]}

To provide more detailed insights into the geographical component of the CDS network, we conduct a country-level decomposition of credit risk contagion in Figure 5. We observe in Figure 5(a) that Spain, France, Germany and Switzerland are the main senders of financial risk, as indicated by the size of their financial sector nodes. The main receivers of financial risk (indicated by color-level) are the non-financial sectors of countries located in the core of Europe (Belgium, France, Germany, Netherlands, Sweden, UK), while the non-financial sectors of countries in the southern periphery (Portugal, Spain, Italy, Greece) are less affected by financial risk shocks. Our findings of a strong cross-border component in the transmission of bank risk in Europe is consistent with the findings of Breckenfelder and Schwaab (2018) with regards to bank-sovereign spillovers. They document that bank risk in stressed eurozone countries spilled over to non-stressed euro area sovereigns during the sovereign debt crisis.

Turning to the transmission of risk from sovereigns to non-financial firms in Figure 5(b) reveals a different geographical pattern. Here, the major senders of risk are the southern European countries Portugal, Spain and Italy, while the contribution of core European countries is much less. In addition, the geographical dispersion of sovereign risk shocks is mainly limited to the periphery, which is the main receiver of shocks as indicated by the magnitude of sovereign-corporate connectedness and the link size between peripheral countries. Conse-

\footnotetext{
${ }^{21}$ See Ang and Longstaff (2013) and De Santis (2012) for evidence on country-specific risk factors in European sovereign CDS spreads.
} 
quently, our results suggest that real-sector contagion of sovereign risk does not spread from the periphery to the center, but remains predominantly a regional phenomenon.

We next assess whether cross-country contagion effects can be explained by the degree of financial linkages between countries. Theoretical work on financial contagion effects suggests that geographically interrelated claims and liabilities in the banking system can facilitate cross-country transmissions of financial shocks (Allen and Gale 2000). We test whether stronger financial linkages between European countries lead to stronger contagion of financial and sovereign risk to the non-financial sector by using data on bilateral bank claims provided by the Bank for International Settlements (BIS) to proxy financial linkages. We distinguish between two aggregates of bilateral bank claims: (i) bilateral bank claims of country $i$ to all sectors of country $j$, and (ii) bilateral bank claims of country $i$ to the non-bank private sector of country $j$. To assess the influence of these two measures of financial linkages on the crosscountry dimension of contagion to the non-financial sector, we then run OLS regressions with the country-level pairwise connectedness measures as the dependent variable and one of the financial linkages proxies as the independent variable.

[TABLE 3 about here]

The results in Table 3 suggest a clear positive relationship between cross-country contagion effects from the financial sector and financial linkages (first column). Countries that share stronger financial linkages experience stronger cross-border contagion between their financial and non-financial sectors than countries with weaker financial linkages. Our results complement empirical findings from studies focusing exclusively on contagion effects within the banking sector. For example, Tonzer (2015) shows that international linkages in interbank markets contribute to the channeling of financial distress across borders. However, our results do not suggest an influence of financial linkages on the magnitude of cross-border contagion effects for sovereign credit risk (second column in Table 3), which highlights again the rather regional nature of the sovereign-real sector risk channel. 


\subsection{Dynamic estimation of the CDS network}

To assess the time-varying nature of the CDS network, we next move to a dynamic framework based on rolling-window (200 days) estimations, with repeated cross validation of the

penalty parameter $\lambda$ and the elastic net mixing parameter $\alpha$ in each window. ${ }^{22}$ Looking at the evolution of connectedness across time allows us to assess whether the propagation of shocks intensified during crisis events, which is consistent with the concept of "shiftcontagion" (Rigobon 2016). Naturally, our emphasis is on the evolution of the network structure following the global financial crisis and the European sovereign debt crisis.

\subsubsection{Global financial crisis}

The critical event in the global financial crisis was Lehman Brother's bankruptcy on September 15, 2008. In Figure 6 we show the CDS network at two different stages for comparison. In (a) the network is depicted for the period before Lehman Brother's bankruptcy (the 200 days window ends on September 1, 2008), while in (b) the network is shown for the period after the Lehman collapse (the 200 days window ends on November 6, 2008).

\section{[FIGURE 6 about here]}

The key pattern that emerges after comparing the two plots is that a large cluster of financial institutions moves from the periphery to the center of the network after Lehman's collapse, reflecting an increase in connectedness of the financial sector to others. An increase in overall transmission of credit risk to others, i.e., the systemic risk component of the financial sector, can be further deduced from the large node size of many financial institutions, such as UBS, Société Générale (SOG) and Deutsche Bank (DBA). As for Lehman's effect on the non-financial sector, we observe that Autos \& Industrials and TMT corporations cluster very close to the financial sector, while the energy sector and most consumer corporations are relatively farther away from the financial center after Lehman's bankruptcy.

\footnotetext{
${ }^{22}$ We also estimate the idiosyncratic components for each window separately.
} 


\subsubsection{European sovereign debt crisis}

To visualize how the CDS network was transformed following the European sovereign debt crisis, we analyze the network graph before and after the onset of the crisis in Figure 7 . We clearly see that connectedness is rather low before the crisis (late-2009), particularly with regards to sovereigns which form their own cluster in the periphery of the network. After the onset of the Eurozone crisis in May 2010 (following the first bailout package for Greece), connectedness increases drastically, thereby fundamentally altering the network's structure. Now we observe that the nodes for sovereign entities moved to the network's center and that the stressed countries Italy, Spain, Ireland and Portugal have very large nodes, which highlights their central role in the crisis. In addition, the sovereign CDS nodes attract a large number of both financial and non-financial corporations that are grouped closely around them. Hence, Figure $7(\mathrm{~b})$ does not only reveal a strong sovereign-financial nexus but it also shows pronounced contagion effects from sovereigns to non-financial corporations during the European debt crisis.

\section{[Figure 7 about here]}

\subsubsection{System-wide connectedness}

Moving from the individual to the aggregate perspective, we depict in Figure 8 the evolution of overall network connectedness, i.e., the degree to which all idiosyncratic CDS returns co-move with each other over time. We observe wide fluctuations in connectedness over the sample period. While system-wide connectedness is at less than $70 \%$ at the beginning of the sample, it shows an increasing trend until the Lehman collapse in late-2008. After a downward trend in 2009, network connectedness jumps substantially following the outbreak of the European debt crisis in early-2010. Throughout 2010 system-wide connectedness remains elevated with several pronounced spikes, reflecting the high degree of financial distress and uncertainty in the Eurozone during this period. The culmination is reached in October and November 2010 when the level exceeds 90 percent, suggesting that markets reacted with a 
fear of more contagion in CDS spreads. ${ }^{23}$

[Figure 8 about here]

In the first quarter of 2011 overall contagion risk decreases noticeably, as evidenced by the drop in system-wide connectedness. The decline in contagion effects resulted from the agreement of euro area leaders on March 11, 2011 to allow the EFSF (European Financial Stability Facility) and the ESM (European Stability Mechanism) to directly intervene in primary markets for sovereign debt. ${ }^{24}$ Over the remainder of the sample period, system-wide connectedness fluctuates persistently, albeit with smaller swings. There is a mild upward trend in connectedness from mid-2012 until early-2017, reflecting that even after the most severe crisis events came to an end, CDS spreads remained tightly linked to each other across all sectors. This indicates that market participants continued to closely monitor conditions in all CDS markets simultaneously.

\subsubsection{Cross-sectoral network connectedness}

With the goal of focusing specifically on temporal fluctuations in credit risk transmission to the non-financial sector, we conduct a sectoral decomposition of connectedness in Figure 9. The results suggest a large degree of heterogeneity in dynamic connectedness across sectors. As for the credit risk shocks from the financial sector, we observe several spikes throughout the sample period. Financial-real sector connectedness is particularly high during the 07/08 global financial crisis and the 2010-12 European debt crisis, providing evidence for contagion effects to the non-financial corporate sector. Interestingly, both the level and the fluctuations

\footnotetext{
${ }^{23}$ This was a crucial stage in the European debt crisis, as concerns about the fiscal strength of Ireland and Portugal prompted markets to expect that a Greek-style program would be extended to these two countries. On October 18, 2010 Angela Merkel and Nicolas Sarkozy surprised markets by announcing that future sovereign bailouts would require 'haircuts' on sovereign bond holdings (also, see Brunnermeier et al. 2016).

${ }^{24}$ Moreover, the resignation of Axel Weber from the Bundesbank presidency in February 2011 may also have contributed to the decrease in contagion risk because markets may have interpreted this event as signalling that after the departure of a major opponent of the ECB's current policy stance at that time, the ECB would further expand its Securities Markets Programme (SMP) in the future.
} 
of connectedness between financial and non-financial corporations increase toward the end of the sample period (2015-2017).

[FIGURE 9 about here]

With regards to sovereign risk (second plot), the dynamic connectedness measure reflects a clear trend. Following the start of the European debt crisis, connectedness rises drastically and then remains at this high level during the most stressing stages of the crisis. In early2011 we observe a considerable decline in the magnitude of sovereign risk transmission. The downward trend continues until early-2014, fluctuations thereafter remain modest. The findings can be interpreted in favor of the ECB's monetary policy stance, as they suggest that the ECB was successful in curbing the contagion effects to the non-financial sector.

As a comparison, we also present intra-sectoral connectedness of non-financial corporations (last plot in Figure 9). It shows almost no fluctuations over time, reflecting that crisis events influenced only the transmission of credit risk from the financial and sovereign sector, but not the transmission of risk within the non-financial sector.

To control for a potential feedback channel running from the non-financial sector to financial institutions and sovereigns, respectively, we also consider the pure net contribution of the financial and sovereign sectors. ${ }^{25}$ Yet, the dynamic evolution of cross-sectoral connectedness remains almost unaffected by this modification. Finally, we break down dynamic connectedness by sub-sectors of corporates which shows that each sub-sector displays somewhat different dynamics, suggesting a role for sector-specific drivers in risk transmission. ${ }^{26}$

\subsubsection{Geographical network connectedness}

The static network analysis already revealed a strong geographical component in the magnitude and direction of credit risk transmission to the non-financial sector. To further inves-

\footnotetext{
${ }^{25}$ This is achieved by subtracting the spillover effects originating in the non-financial sector from those operating in the opposite direction. The results are presented in the Online Appendix (Figure OA.2).

${ }^{26}$ See Figure OA.3 in the Online Appendix.
} 
tigate geographical patterns in a dynamic framework, we differentiate between two groups of risk senders at the country-level and calculate the evolution of risk transmission for each group separately. We form a group of GIIPS banks, i.e., financial institutions headquartered in the so-called "GIIPS" countries (Greece, Ireland, Italy, Portugal, Spain) and a group of non-GIIPS banks, i.e., financial corporations headquartered in "non-GIIPS", or "core", countries (Belgium, France, Germany, Netherlands, Switzerland, UK). Moreover, to capture possible geographical differences in the transmission of sovereign risk, we adopt the same grouping procedure for "GIIPS" and "non-GIIPS" sovereigns.

\section{[FIGURE 10 about here]}

Figure 10 shows each country group's contribution to financial and sovereign risk transmission over time. As for the risk transmission from the financial sector to non-financial corporations (first plot), the difference between the two country groups appears to be small. For most of the sample period the two separate connectedness measures move in tandem. In 2010, we observe a relatively stronger contribution from banks in GIIPS countries. In the second half of the sample (2013-2017), financial shocks from non-GIIPS banks are typically stronger than those from GIIPS banks.

Regarding risk transmission from the sovereign sector, the difference in contributions between GIIPS and non-GIIPS is sizeable, as visible in the second plot of Figure 10. With the beginning of the sovereign debt crisis in early-2010, risk shocks from GIIPS sovereigns increased relatively more than risk shocks from non-GIIPS sovereigns. In terms of magnitude, our estimates suggest that at the height of the sovereign debt crisis in 2010, sovereign risk shocks transmitted from GIIPS sovereigns to non-financial corporations are roughly twice as strong as risk shocks transmitted from non-GIIPS sovereigns.

In 2011, connectedness decreases for both country groups. But while connectedness from non-GIIPS sovereigns returns to its pre-crisis level in 2011, that of stressed GIIPS countries remains elevated throughout 2011 as a result of continuing political and economic tensions 
in these countries. Only in the first half of 2012, the level of sovereign risk transmission from GIIPS sovereigns converges back to that of non-GIIPS countries, possibly as an outcome of the more aggressive ECB policy stance under the new president Mario Draghi. ${ }^{27}$ From mid2012 onwards, sovereign connectedness remains relatively stable, with both country groups contributing about the same amount of credit risk. This changes in 2015, where we observe another increase in contagion from GIIPS-sovereigns as a consequence of uncertainties regarding the newly elected Syriza-government in Greece.

\subsection{Model evaluation and comparison}

In this section we carry out a number of exercises to evaluate our methodology and to compare our approach to alternative model specifications and modelling approaches.

\subsubsection{Performance and properties of elastic net estimator}

By design the elastic net estimator chooses the best model (lowest error) in-sample by jointly selecting the elastic net mixing parameter $\alpha$ and the penalty tuning parameter $\lambda$. To evaluate the out-of-sample performance of our methodology we conduct a forecasting exercise in which we split our sample in an in-sample-period from 23/10/2006 to 31/12/2014 and an out-ofsample period from $02 / 01 / 2015$ to $28 / 07 / 2017$. We first estimate our elastic net model in-sample using the methodology described in previous sections and then use the fitted values to evaluate the model in the out-of-sample period. We compare the elastic net model to the following competitor models: (i) the constant mean model which uses the in-sample mean of each variable as forecasts, (ii) the $\mathrm{AR}(1)$ model which conducts forecasts based on the fitted values from a persistent process, (iii) the ridge estimator which applies shrinkage in the VAR with $\alpha=1$, and (iv) the constant elastic net estimator which uses a fixed elastic net mixing parameter of $\alpha=0.5$ and chooses only the optimal $\lambda$ in the penalty function.

\footnotetext{
${ }^{27}$ After Mario Draghi took office as the new president of the ECB in November 2011, the governing council lowered interest rates in two steps by a combined 0.5 percent to 1 percent over the course of five weeks. In addition to these measures, the ECB announced at the December 2011 meeting two exceptional longer-term refinancing operations (LTRO), which provided unlimited amounts of liquidity to banks with a three-year maturity.
} 
Table 4 shows the results of the forecasting exercise for our elastic net estimator (first row) and the competitor models (rows 2-5). It is shown that the elastic net model performs best out-of-sample relative to the competing models, since it produces on average the lowest MSE for the total sample.

\section{[TABLE 4 about here]}

To provide insights into the properties of the elastic net parameters $\alpha$ and $\lambda$ in the dynamic framework we plot their distribution over the sample period for different window sizes (150, 200, and 250 days) in Figure $11 .^{28}$ The mixing parameter $\alpha$ does not fluctuate much over the sample period, remaining in the range between 0.1 and 0.3 for the most part, which is close to the LASSO estimator $(\alpha=0)$. The distribution of $\alpha$ is very similar across the different window sizes, indicating that the mixing parameter is little affected by the choice of window size. There are more dynamics at work for the penalty tuning parameter $\lambda$ (Figure 11(b)). It is larger at the beginning of the sample but then declines with the onset of the global financial crisis, suggesting that the larger degree of interconnectedness after the crisis start leads the elastic net estimator to penalize the parameters less to find the optimal model fit. The lowest values for $\lambda$ are observed for the peak of the sovereign debt crisis (2010-11), which is also the period for which our measure of system-wide connectedness (Figure 8) shows the highest estimates. As for the impact of the window size on $\lambda$, we observe that, in general, a smaller window leads to a slightly larger penalty (higher values for $\lambda$ ).

[FiguRE 11 about here]

\subsubsection{Comparison with Granger-causality network}

The econometric approach used in this paper uses variance decompositions to characterize the network. An alternative approach is to focus on the short-term VAR coefficient matrices as

\footnotetext{
${ }^{28} \mathrm{We}$ are grateful to an anonymous referee for this helpful suggestion.
} 
e.g. in Billio et al. (2012) who use pairwise Granger-causality to characterize the network. ${ }^{29}$ The Granger-causality approach is less granular than the variance-decomposition approach as it only tests whether coefficients are zero or non-zero without taking into account the magnitude of non-zero coefficients. Nevertheless, to provide a comparison to our approach, which should be viewed rather as a complement than a substitute, we implement the Grangercausality approach to a large-dimensional setting by defining connectedness as the number of short-run spillover coefficients in the VAR that are not shrunk toward 0 by elastic net. ${ }^{30}$

[FIgURE 12 about here]

Figure 12 shows the resulting system-wide connectedness for the dynamic framework (200 days rolling-window), which depicts the percentage of non-zero links for each window. It is thus the Granger-causality analogue to Figure 8. A strong increase in connectedness is visible in the run-up to the global financial crisis, while after the crisis Granger-causality links indicate a number of fluctuations but with no clear discernible trend. This suggests that the Granger-causality measure is lacking the granularity, in particular compared to the variance decomposition approach pursued in this paper, to serve as a helpful tool in monitoring systemic risks in quasi real-time. ${ }^{31}$

\subsubsection{Robustness checks}

We conduct robustness checks for the static (full-sample) framework for (i) different forecast horizons and (ii) a 2-factor specification. In the Online Appendix we depict the visualized networks resulting from these alternative model specifications. It is shown that changing

\footnotetext{
${ }^{29}$ We thank an anonymous referee for the suggestion to compare our approach with an alternative empirical framework.

${ }^{30}$ Note that we do not consider significance of the coefficients since direct model inference after variable selection via LASSO or elastic net is not valid, because the $p$-values are distorted since the variables that are selected will tend to be those that are significant (Tibshirani et al. 2016).

${ }^{31}$ The results for cross-sectoral connectedness in the static (full-sample) framework based on the Grangercausality approach are reported in Figure OA.4 in the Online Appendix. It shows that the differences across sectors are substantially less pronounced compared to the variance decomposition approach, suggesting that, similar to the dynamic framework, the unweighted (i.e., zero vs. non-zero) Granger-causality approach may mask important dependencies among variables.
} 
the forecast horizon to 5, 15 or 20 days has very little impact on the network structure as the visualizations look almost identical. The 2-factor specification leads to more visible changes in the network structure, which is not surprising given that the additional factor removes correlation from the variables in the sample. However, the main findings remain qualitatively similar: we observe a strong clustering of sectors and a dominant financial sector which is an important transmitter of shocks to non-financial corporations. Beyond visual inspections we evaluate robustness in a more formal way by computing bivariate correlation coefficients for the rankings of the most important senders/receivers between the baseline model and alternative specifications (Table OA.2). The correlation coefficients are all statistically significantly positive and all except one are very close to 1 , thus indicating that the network structure does not change substantially if alternative model specifications are chosen.

For the time-varying framework we focus on the sensitivity of results to different window sizes. Figure OA.9 reports the measure for system-wide connectedness using windows of 150 days, 200 days (baseline) and 250 days. We observe that the dynamic pattern of the systemwide connectedness measures are comparable across window sizes. For example, both the Lehman bankruptcy and the outbreak of the European sovereign debt crisis are captured by all window specifications. As expected, a smaller window size produces a slightly more sensitive measure as reflected in larger spikes and drops, in particular for the window size of 150 days. Moreover, a change in the window size results in a small level shift of the system-wide connectedness measure in that a smaller window size produces on average a slightly larger degree of connectedness at each point in time.

\section{Conclusions}

Motivated by the scant empirical evidence on the propagation of credit risk shocks from financial institutions and sovereigns to the non-financial sector of the economy, we conduct a network analysis using 152 CDS series for European financial institutions, sovereigns and 
non-financial corporations over the period from October 2006 to July 2017. Our methodology relies on recent techniques to measure and visualize connectedness in large-dimensional systems of financial variables. Our main findings suggest a sectoral clustering in the CDS network, where financial institutions are located in the center of the network and non-financial as well as sovereign CDS are grouped around the financial center, reflecting the systemic importance of the financial sector in Europe. We also detect a geographical component in the network, as evidenced by differences in risk transmission across countries.

Our methodological framework is flexible enough to provide time-varying estimates of the CDS network, which can be a useful tool for systemic risk monitoring. We show that both the Lehman bankruptcy and the European debt crisis fundamentally transformed the network structure. By contrast, we find that the transmission of risk within the non-financial sector remained largely unchanged during the crisis events. Taken together, our results indicate that bank and sovereign risk are important drivers of corporate credit risk. Out-of-sample evaluations and comparisons with alternative approaches show that our estimator performs relatively better and provides more granular estimates of connectedness.

Our network analysis identified the source, direction and relative size of credit risk shocks to the non-financial sector in Europe. Future research could further include the sign of the shocks' impact as additional information in the characterization of the network, as in Dungey et al. (2017). A signed network would reflect whether a shock to one entity has an amplifying or dampening effect on each of the other entities in the system. This approach would take into account that contagion is more likely between nodes that are linked through positive weights rather than negative weights. 


\section{References}

Abildgren, K., Buchholst, B. V., and Staghøj, J. (2013). Bank-Firm Relationships and the Survival of Non-Financial Firms During the Financial Crisis 2008-2009, ECB Working Paper No. 1516.

Acemoglu, D., Carvalho, V. M., Ozdaglar, A., Tahbaz-Salehi, A. (2012). The Network Origins of Aggregate Fluctuations, Econometrica 80, 1977-2016.

Acemoglu, D., Ozdaglar, A., and Tahbaz-Salehi, A. (2015). Systemic Risk and Stability in Financial Networks, American Economic Review 105, 564-608.

Acharya, V., Drechsler, I., and Schnabl, P. (2014). A Pyrrhic Victory? Bank Bailouts and Sovereign Credit Risk, The Journal of Finance 69, 2689-2739.

Allen, F., and Gale, D. (2000). Financial Contagion, Journal of Political Economy 108, 1-33.

Almeida, H., Cunha, I., Ferreira, M. A., and Restrepo, F. (2017). The Real Effects of Credit Ratings: The Sovereign Ceiling Channel, The Journal of Finance 72, 249-290.

Alter, A., and Beyer, A. (2014). The Dynamics of Spillover Effects during the European Sovereign Debt Turmoil, Journal of Banking and Finance 42, 134-153.

Ang, A., and Longstaff, F. A. (2013). Systemic Sovereign Credit Risk: Lessons from the U.S. and Europe, Journal of Monetary Economics 60, 493-510.

Augustin, P., Subrahmanyam, M. G., Tang, D. Y., and Wang, S. Q. (2014). Credit Default Swaps: A Survey, Foundations and Trends in Finance 9, 1-196.

Augustin, P., Boustanifar, H., Breckenfelder, J., and Schnitzler, J. (2018). Sovereign to Corporate Risk Spillovers, Journal of Money, Credit and Banking 50, 857-891.

Barigozzi, M., and Hallin, M. (2017). A Network Analysis of the Volatility of High-Dimensional Financial Series, Journal of the Royal Statistical Society Applied Statistics Series C $66,581-605$.

Bedendo, M., and Colla, P. (2015). Sovereign and Corporate Credit Risk: Evidence from the Eurozone, Journal of Corporate Finance 33, 34-52.

Berndt, A., and Obreja, I. (2010). Decomposing European CDS Returns, Review of Finance 14, 189-233.

Betz, F., Hautsch, N., Peltonen, T. A., and Schienle, M. (2016). Systemic Risk Spillovers in the European Banking and Sovereign Network, Journal of Financial Stability 25, 206-224.

Billio, M., Getmansky, M., Lo, A. W., and Pelizzon, L. (2012). Econometric Measures of Connectedness and Systemic Risk in the Finance and Insurance Sectors, Journal of Financial Economics 104, 535-559.

Blanco, R., Brennan, S., and Marsh, I. W. (2005). An Empirical Analysis of the Dynamic Relation between Investment-Grade Bonds and Credit Default Swaps, The Journal of Finance 60, 2255-2281. 
Bongaerts, D., De Jong, F., and Driessen, J. (2011). Derivative Pricing with Liquidity Risk: Theory and Evidence from the Credit Default Swap Market, The Journal of Finance 66, 203-240.

Borensztein, E., Cowan, K., and Valenzuela, P. (2013). Sovereign Ceilings "Lite"? The Impact of Sovereign Ratings on Corporate Ratings, Journal of Banking and Finance 37, 4014-4024.

Breckenfelder, J., and Schwaab, B. (2018). Bank to Sovereign Risk Spillovers across Borders: Evidence from the ECB's Comprehensive Assessment, Journal of Empirical Finance 49, 247-262.

Brillinger, D. R. (1981). Time Series: Data Analysis and Theory, San Francisco: Holden Day.

Brunnermeier, M. K., James, H., and Landau, J.-P. (2016). The Euro and the Battle of Ideas. Princeton: Princeton University Press.

Bühler, W., and Trapp, M. (2009). Time-Varying Credit Risk and Liquidity Premia in Bond and CDS Markets, CFR Working Paper No. 09-13.

Chinazzi, M., and Fagiolo, G. (2015). Systemic Risk, Contagion, and Financial Networks: A Survey, in: Fernández, I. A., and Ausina, E. T. (eds.). Banking Integration and Financial Crisis: Some Recent Developments, Bilbao: Fundación BBVA, Chapter 4 , 115-161.

Corò, F., Dufour, A., and Varotto, S. (2013). Credit and Liquidity Components of Corporate CDS Spreads, Journal of Banking and Finance 37, 5511-5525.

De Bandt, O., Hartmann, P., and Peydró, J. L. (2009). Systemic Risk in Banking: An Update, in: Berger, A. N., Molyneux, P., and Wilson, J. O. (eds). The Oxford Handbook of Banking, Oxford: Oxford University Press.

Collin-Dufresne, P., and Goldstein, R. S. (2001). Do Credit Spreads Reflect Stationary Leverage Ratios?, The Journal of Finance 56, 56, 1929-1957.

Collin-Dufresne, P., Goldstein R. S., and Martin, J. S. (2001). The Determinants of Credit Spread Changes, The Journal of Finance 56, 2177-2207.

De Bruyckere, V., Gerhardt, M., Schepens, G., and Vennet, R. V. (2013). Bank/Sovereign Risk Spillovers in the European Debt Crisis, Journal of Banking and Finance 37, 47934809.

De Santis, R. A. (2012). The Euro Area Sovereign Debt Crisis: Safe Haven, Credit Rating Agencies and the Spread of the Fever from Greece, Ireland and Portugal, ECB Working Paper No. 1419.

Demirer, M., Diebold, F. X., Liu, L., and Yilmaz, K. (2018). Estimating Global Bank Network Connectedness, Journal of Applied Econometrics 33, 1-15.

Diebold, F. X., and Yilmaz, K. (2009). Measuring Financial Asset Return and Volatility Spillovers, with Application to Global Equity Markets, The Economic Journal 119, 158-171. 
Diebold, F. X., and Yilmaz, K. (2012). Better to Give than to Receive: Predictive Directional Measurement of Volatility Spillovers, International Journal of Forecasting 28, 57-66.

Diebold, F. X., and Yilmaz, K. (2014). On the Network Topology of Variance Decompositions: Measuring the Connectedness of Financial Firms, Journal of Econometrics 182, 119-134.

Dungey, M., Harvey, J., Siklos, P., and Volkov, V. (2017). Signed Spillover Effects Building on Historical Decompositions, Tasmanian School of Business and Economics Discussion Paper Series No. 2017-11.

Elliott, M., Golub, B., and Jackson, M. O. (2014). Financial Networks and Contagion, The American Economic Review 104, 3115-3153.

Eom, Y.-H., Helwege, J., and Huang, J.-Z. (2004). Structural Models of Corporate Bond Pricing: An Empirical Analysis, Review of Financial Studies 17, 499-544.

European Central Bank (ECB) (2009). The Importance of Insurance Companies for Financial Stability, in: Financial Stability Review December 2009, 160-168.

European Central Bank (ECB) (2011). Systemic Risk Methodologies, Financial Stability Review June 2011, 141-148.

Faccio, M., Masulius, R. W., and McConnell, J. J. (2006). Political Connections and Corporate Bailouts, The Journal of Finance 61, 2597-2635.

Financial Stability Board (FSB) (2011). Policy Measures to Address Systemically Important Financial Institutions, Url: http://www.fsb.org/2011/11/r_111104bb/.

Financial Stability Board (FSB) (2014). 2014 Update of List of Global Systemically Important Banks (G-SIBs), Url: http://www.financialstabilityboard.org/wp-content/uploads/ r_141106b.pdf.

Financial Stability Board (FSB) (2016). List of Global Systemically Important Insurers (GSIIs), Url: http://www.fsb.org/2016/11/2016-list-of-global-systemically-importantinsurers-g-siis/.

Forni, M., Hallin, M., Lippi, M., and Reichlin, L. (2000). The Generalized Dynamic Factor Model: Identification and Estimation, Review of Economics and Statistics 82, 540-554.

Forni, M., Hallin, M., Lippi, M., and Zaffaroni, P. (2015). Dynamic Factor Models with Infinite-Dimensional Factor Spaces: One-Sided Representations, Journal of Econometrics 185, 359-371.

Forni, M., Hallin, M., Lippi, M., and Zaffaroni, P. (2017). Dynamic Factor Models with Infinite-Dimensional Factor Spaces: Asymptotic Analysis, Journal of Econometrics 199, 74-92.

Forni, M., and Lippi, M. (2001). The Generalized Dynamic Factor Model: Representation Theory, Econometric Theory 17, 1113-1141.

Fruchterman, T. M. J., and Reingold, E. M. (1991). Graph Drawing by Force-Directed Placement, Software - Practice and Experience 21, 1129-1164. 
Glasserman, P., and Young, H. P. (2015). How Likely is Contagion in Financial Networks?, Journal of Banking and Finance 50, 383-399.

Glasserman, P., and Young, H. P. (2016). Contagion in Financial Networks, Journal of Economic Literature 54, 779-831.

Hallin, M., and Liška, R. (2007). Determining the Number of Factors in the General Dynamic Factor Model, Journal of the American Statistical Association 102, 603-617.

Hasman, A. (2013). A Critical Review of Contagion Risk in Banking, Journal of Economic Surveys 27, 978-995.

Huang, J.-Z., and Zhou, H. (2008). Specification Analysis of Structural Credit Risk Models, Working Paper.

International Monetary Fund (IMF) (2013). Global Financial Stability Report: Transition Challenges to Stability, October 2013: Washington D.C..

IMF/FSB/BIS (2009). Guidance to Assess the Systemic Importance of Financial Institutions, Markets and Instruments: Initial Considerations-Report to the G-20 Finance Ministers and Central Bank Governors.

Koop, G., Pesaran, M. H., and Potter, S. M. (1996). Impulse Response Analysis in NonLinear Multivariate Models, Journal of Econometrics 74, 119-147.

Leland, H., and Toft, K. (1996). Optimal Capital Structure, Endogenous Bankruptcy, and the Term Structure of Credit Spreads, The Journal of Finance 51, 987-1019.

Longstaff, F. A., Mithal, S., and Neis, E. (2005). Corporate Yield Spreads: Default Risk or Liquidity? New Evidence from the Credit Default Swap Market, The Journal of Finance 60, 2213-2253.

Longstaff, A., and Schwartz, E. (1995). A Simple Approach to Valuing Risky Fixed and Floating Rate Debt, The Journal of Finance 50, 789-819.

Minamihashi, N. (2011). Credit Crunch Caused by Bank Failures and Self-Selection Behavior in Lending Markets, Journal of Money, Credit and Banking 43, 133-161.

Palladini, G., and Portes, R. (2011). Sovereign CDS and Bond Pricing Dynamics in the Euro-Area, NBER Working Paper No. 17586.

Pesaran, M. H., and Shin, Y. (1998). Generalized Impulse Response Analysis in Linear Multivariate Models, Economics Letters 58, 17-29.

Rey, H. (2015). Dilemma Not Trilemma: The Global Financial Cycle and Monetary Policy Independence, NBER Working Paper No. 21162.

Rigobon, R. (2016). Contagion, Spillover and Interdependence, Bank of England Staff Working Paper No. 607.

Tibshirani, R. (1996). Regression Shrinkage and Selection via the Lasso, Journal of the Royal Statistical Society 58, 267-288. 
Tibshirani, R. J., Taylor, J., Lockhart, R., and Tibshirani, R. (2016). Exact Post-Selection Inference for Sequential Regression Procedures, Journal of the American Statistical Association, 111,600-620.

Tonzer, L. (2015). Cross-Border Interbank Networks, Banking Risk and Contagion, Journal of Financial Stability 18, 19-32.

Zhang, B. Y., Zhou, H., and Zhu, H. (2009). Explaining Credit Default Swap Spreads with the Equity Volatility and Jump Risks of Individual Firms, Review of Financial Studies $22,5099-5131$.

Zou, H., and Hastie, T. (2005). Regularization and Variable Selection Via the Elastic Net, Journal of the Royal Statistical Society 67, 301-320. 
Figure 1: Evolution of common factor over sample period

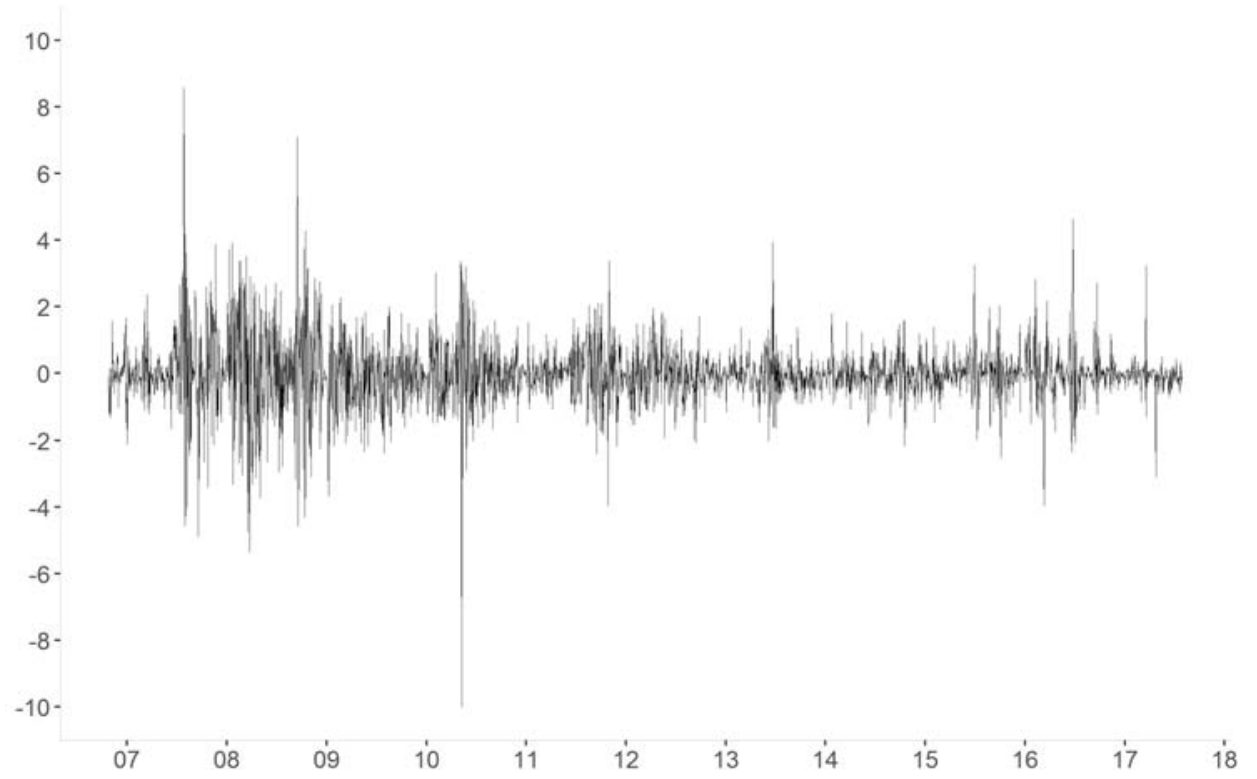

Table 1: Properties of the common factor

Panel A: Variance explained by the common factor

\begin{tabular}{llllllll} 
Sector & $\begin{array}{l}\text { Autos \& } \\
\text { Industrials }\end{array}$ & Consumers & Energy & TMT & Financial & Sovereign & All CDS \\
\hline$R^{2}$ & 0.455 & 0.439 & 0.438 & 0.459 & 0.444 & 0.094 & $\mathbf{0 . 3 3 7 3}$
\end{tabular}

Panel B: Correlation with global uncertainty (VIX)

\begin{tabular}{llll}
$\rho\left(F_{t}, \Delta V I X_{t}\right)$ & $\Delta V I X_{t}$ & $\Delta V I X_{t-1}$ & $R^{2}$ \\
\hline 0.326 & $0.047^{* * *}$ & $0.035^{* * *}$ & 0.174 \\
\hline
\end{tabular}

Note: Panel A shows the explanatory power $\left(R^{2}\right)$ of the common factor for individual CDS returns averaged by sector. In Panel $\mathrm{B}$ we investigate the link between the common CDS factor and global uncertainty as proxied by the VIX. $\rho\left(F_{t}, \Delta V I X_{t}\right)$ is the Pearson's correlation coefficient, $\Delta V I X_{t}, \Delta V I X_{t-1}$ and $R^{2}$ are the estimates of regressing the common factor $F_{t}$ on VIX returns (contemporaneous and first lag): $F_{t}=c+\Delta V I X_{t}+\Delta V I X_{t-1}+\varepsilon_{t} .{ }^{* * *}$ denotes significance at the $1 \%$ level based on Newey-West standard errors. 
Figure 2: CDS network graph for full-sample period (2006-2017)

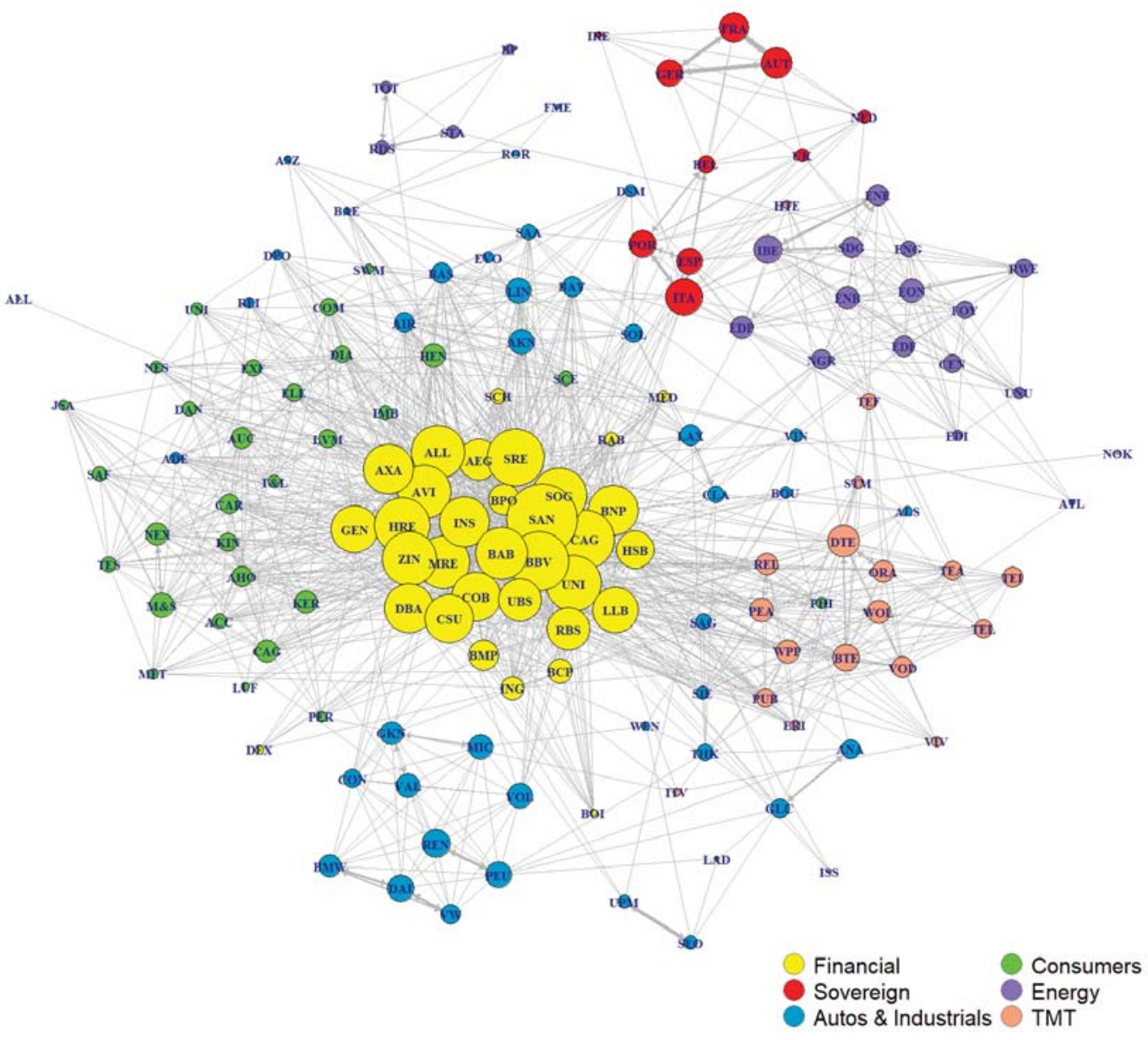

Note: The network pictured above is estimated using forecast error variance decompositions in a 'factor plus sparse' VAR. The position of links and nodes is determined by the force-directed algorithm of Fruchterman and Reingold (1991). 
Table 2: Ranking of largest senders and receivers of credit risk

(a) Financial $\rightarrow$ Non-Financial

\begin{tabular}{llc}
\multicolumn{2}{c}{ Sender } \\
\hline Rank & Name & $\begin{array}{c}\text { Connected- } \\
\text { ness "To" }\end{array}$ \\
\hline 1 & Santander & 0.58 \\
2 & Crédit Agricole & 0.54 \\
3 & Swiss RE & 0.52 \\
4 & Société Générale & 0.49 \\
5 & BBVA & 0.49 \\
6 & Hannover Rueck & 0.47 \\
7 & Zurich Insurance & 0.46 \\
8 & Munich RE & 0.45 \\
9 & Allianz & 0.44 \\
10 & Unicredit & 0.43 \\
$\vdots$ & $\quad \vdots$ & $\vdots$ \\
29 & Standard Chartered & 0.17 \\
30 & Rabobank & 0.14 \\
31 & Dexia & 0.13 \\
32 & Mediobanca & 0.11 \\
33 & Bank of Ireland & 0.08 \\
\hline
\end{tabular}

\begin{tabular}{llc}
\multicolumn{2}{c}{ Receiver } \\
\hline Rank & Name & $\begin{array}{c}\text { Connected- } \\
\text { ness "From" }\end{array}$ \\
\hline 1 & Air Liquide & 0.81 \\
2 & Henkel & 0.77 \\
3 & Ahold Delhaize & 0.73 \\
4 & Svenska Cellulosa & 0.73 \\
5 & Bayer & 0.66 \\
6 & Akzo Nobel & 0.65 \\
7 & Carrefour & 0.64 \\
8 & Accor & 0.63 \\
9 & Relx & 0.63 \\
10 & Casino Guichard & 0.62 \\
$\vdots$ & $\quad \vdots$ & $\vdots$ \\
105 & Hellenic Telecom & 0.07 \\
106 & RWE & 0.07 \\
107 & BP & 0.07 \\
108 & Iberdrola & 0.06 \\
109 & Nokia & 0.04 \\
\hline
\end{tabular}

(b) Sovereign $\rightarrow$ Non-Financial

\begin{tabular}{llc}
\multicolumn{2}{c}{ Sender } \\
\hline Rank & Name & $\begin{array}{c}\text { Connected- } \\
\text { ness "To" }\end{array}$ \\
\hline 1 & Italy & 0.28 \\
2 & Portugal & 0.22 \\
3 & Spain & 0.21 \\
4 & UK & 0.12 \\
5 & Austria & 0.12 \\
6 & Germany & 0.11 \\
7 & France & 0.11 \\
8 & Belgium & 0.11 \\
9 & Netherlands & 0.11 \\
10 & Ireland & 0.09 \\
\hline
\end{tabular}

Note: The connectedness measures in all tables above are normalized by the number of entities so that the results represent the average value per entity.

\begin{tabular}{llc}
\multicolumn{2}{c}{ Receiver } \\
\hline Rank & Name & $\begin{array}{c}\text { Connected- } \\
\text { ness "From" }\end{array}$ \\
\hline 1 & Energias de Portugal & 0.56 \\
2 & ENEL & 0.47 \\
3 & Telefonica & 0.43 \\
4 & National Grid & 0.39 \\
5 & Électricité de France & 0.39 \\
6 & Iberdrola & 0.36 \\
7 & EON & 0.35 \\
8 & Hellenic Telecom & 0.34 \\
9 & ENBW & 0.34 \\
10 & ENGIE & 0.32 \\
$\vdots$ & $\vdots$ & $\vdots$ \\
105 & Michelin & \\
106 & Glencore & 0.03 \\
107 & Metro & 0.03 \\
108 & Volvo & 0.03 \\
109 & Alliance Boots & 0.02 \\
\hline
\end{tabular}


Figure 3: Individual senders of financial risk

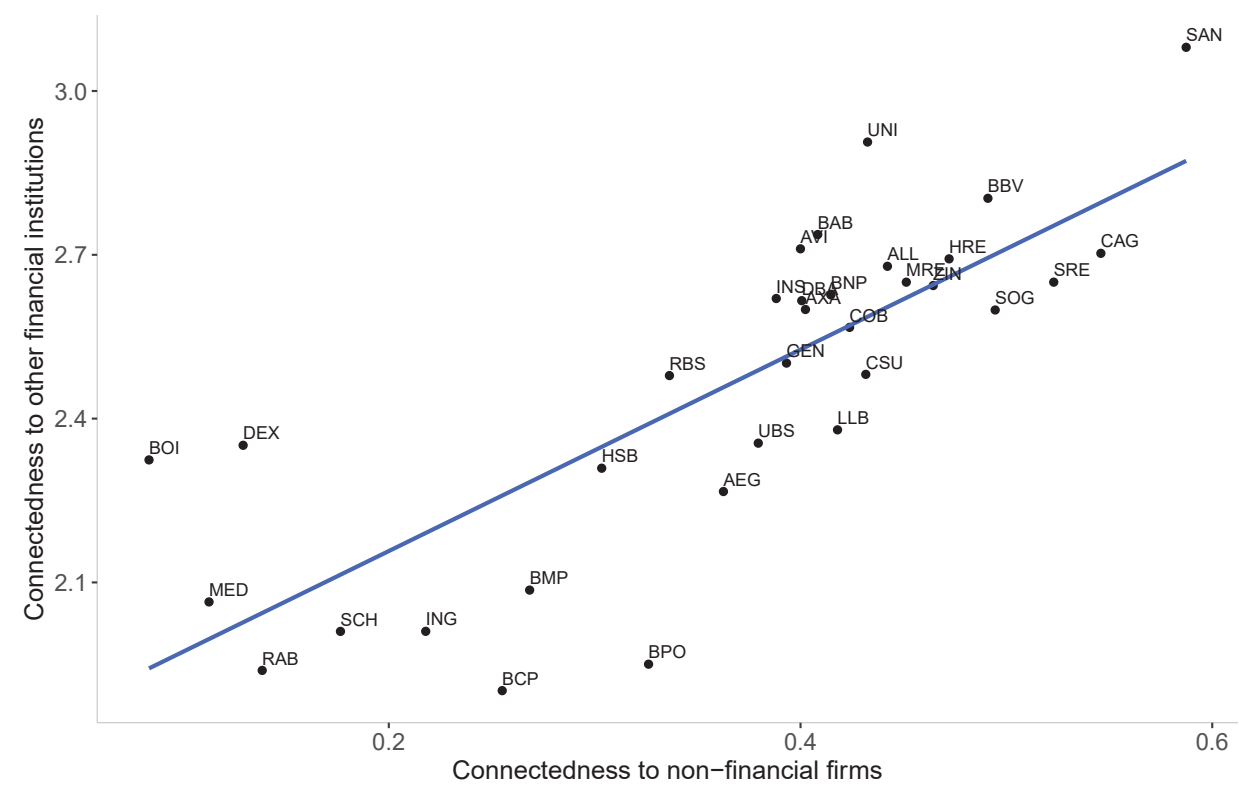

Note: The plot shows the relationship between financial institutions' total connectedness to other financial institutions and financial institutions' total connectedness to non-financial firms over the full-sample period (2006-2017).

Figure 4: Aggregate cross-sectoral connectedness

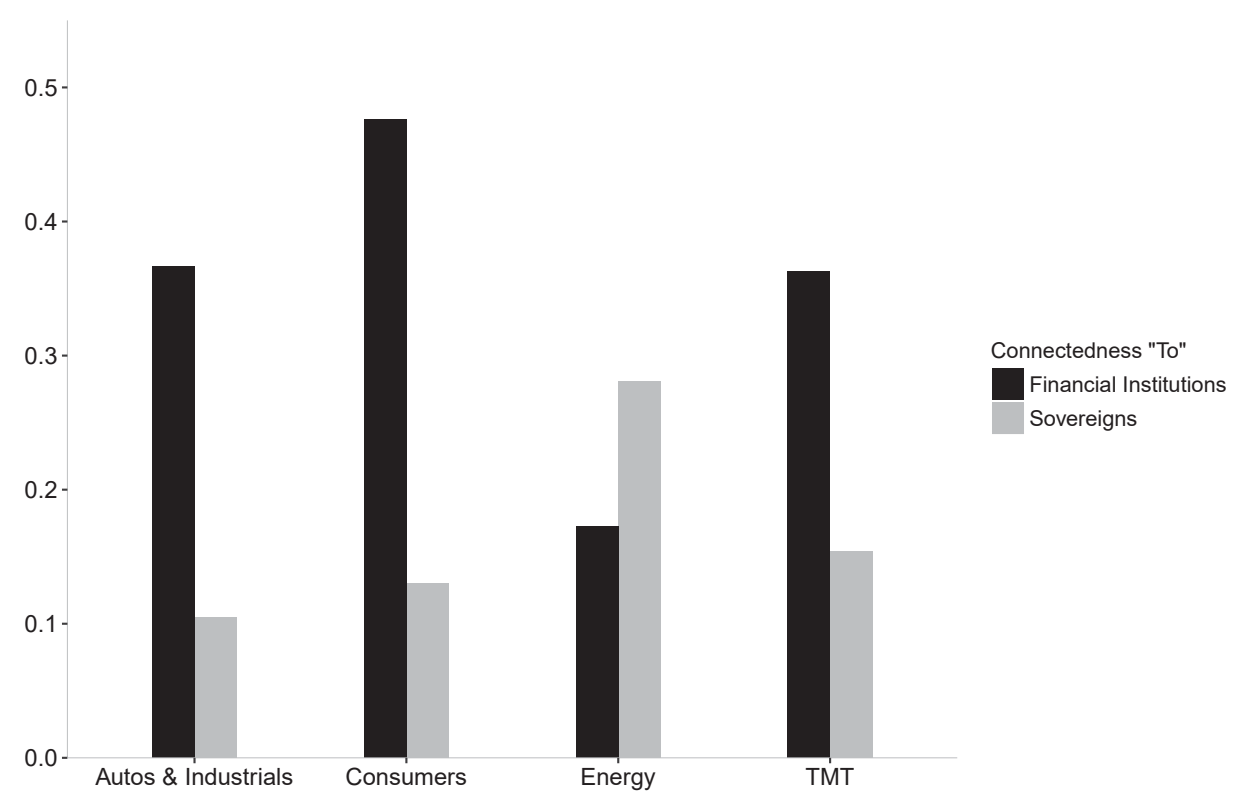

Note: The plot shows directional connectedness from financials and sovereigns, respectively, to non-financial firms, aggregated by sector type for the full-sample period (2006-2017). To ensure comparability, the aggregate measures are normalized by the number of entities so that the measures reported above represent average connectedness per entity of the corresponding sector. 
Figure 5: Geographical connectedness

(a) Financial $\rightarrow$ Non-Financial

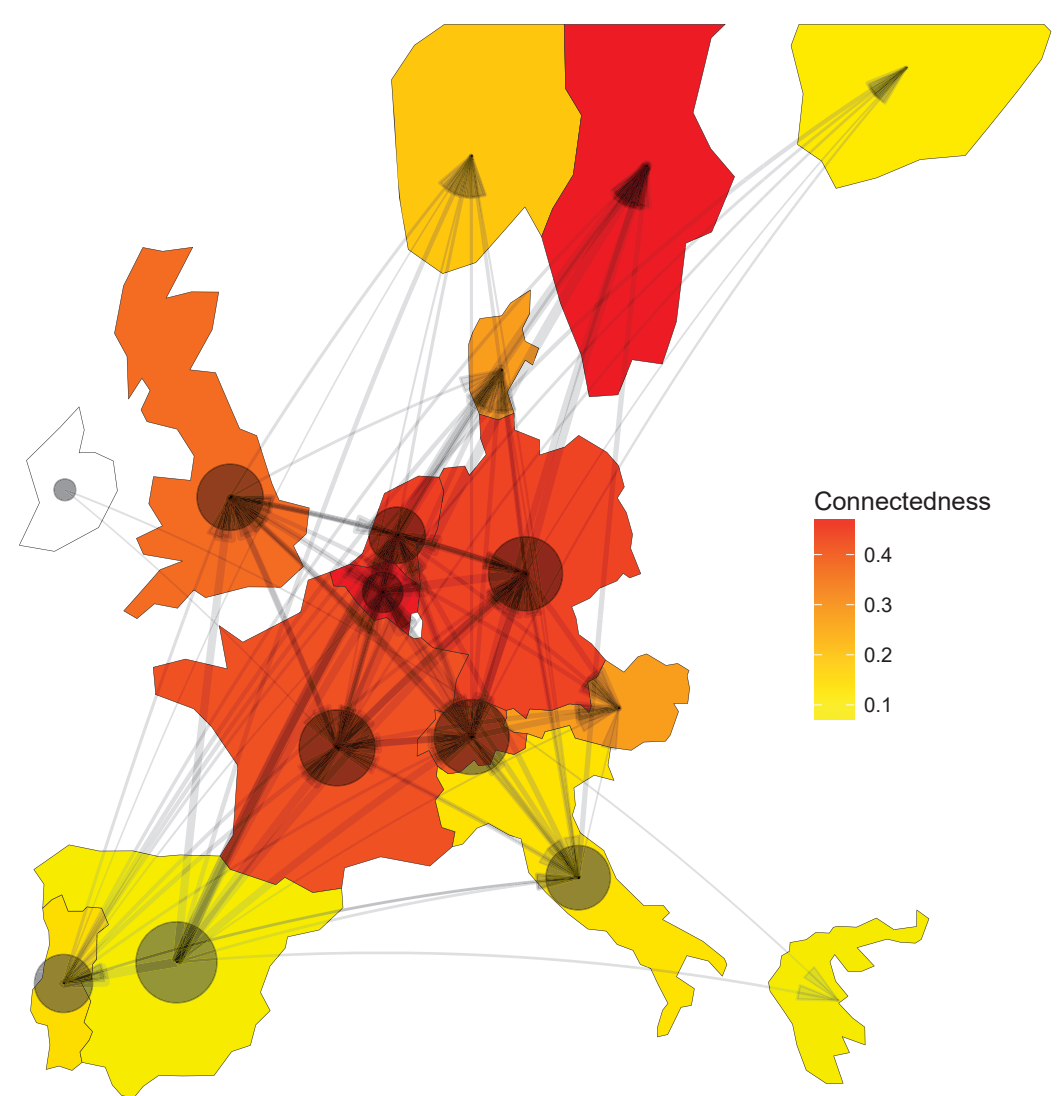

(b) Sovereign $\rightarrow$ Non-Financial

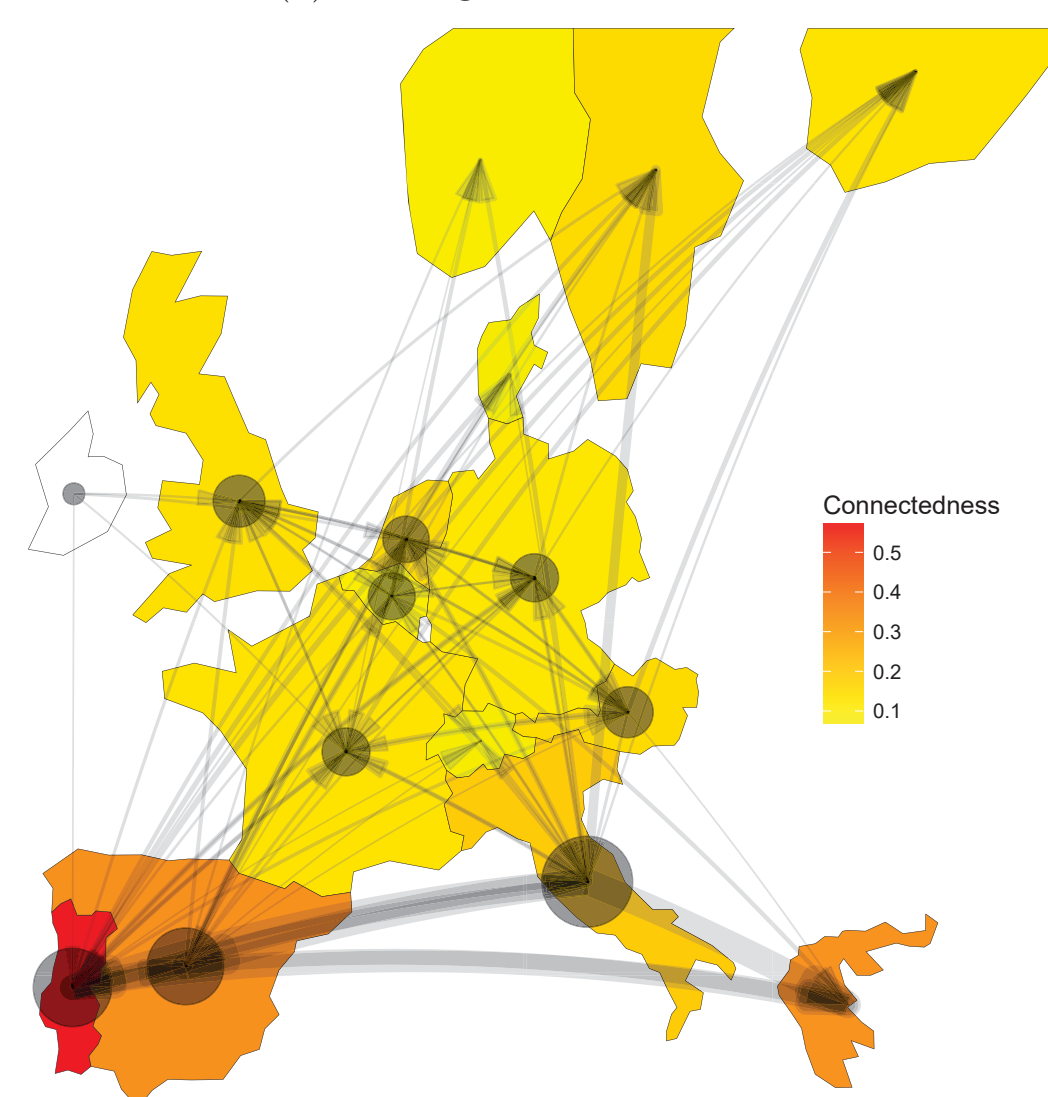

Note: The plot shows the geographical (country-level) decomposition of directional connectedness between (a) financial and non-financial entities and (b) between sovereign and non-financial entities. The color level of each country indicates the magnitude of credit risk shocks to non-financial firms headquartered in the corresponding country (country aggregates of "from" connectedness). The size of the black nodes indicates the contribution of (a) financial institutions or (b) sovereigns located in the corresponding country (country aggregates of "to" connectedness). Link thickness reflects the degree of cross-country "from" connectedness of non-financial firms (thicker links between any two countries represent a stronger cross-country risk transfer to non-financials). Ireland is left blank, as there are no non-financial firms from Ireland in our sample. To ensure comparability all country aggregates are normalized by the number of entities so that the results reported above represent average connectedness by country and sector. 
Table 3: Geographical connectedness and financial linkages

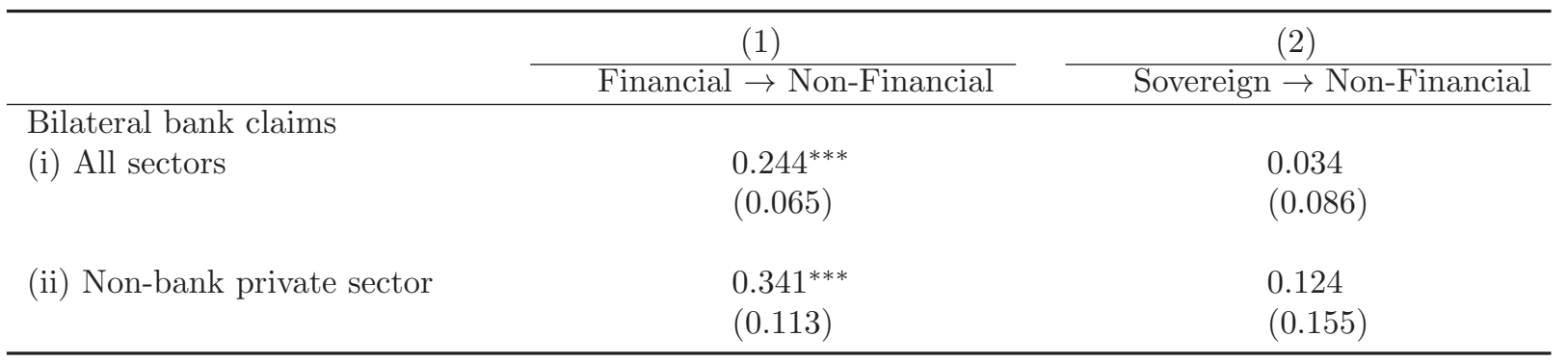

Note: The table reports the results of regressing the pairwise cross-country connectedness measures on bilateral bank claims from the consolidated banking statistics database of the Bank for International Settlements (BIS). We differentiate between (i) bilateral bank claims of country $i$ to all sectors of country $j$, and (ii) bilateral bank claims of country $i$ to the non-bank private sector of country $j$. We divide bilateral bank claims by country $j$ 's GDP to control for economy size. The BIS consolidated banking statistics measure banks' country risk exposures by capturing the claims of banks' foreign affiliates (ultimate risk basis). This consolidation approach is consistent with our strategy of aggregating the connectedness measures by the geographical location of a bank's headquarter. Each OLS regression includes a constant and country dummies. Standard errors are in parentheses. *** denotes significance at the $1 \%$ level.

Table 4: Out-of-sample forecast results

\begin{tabular}{lccccccc}
\hline & $\begin{array}{l}\text { Autos \& } \\
\text { Industrials }\end{array}$ & Consumers & Energy & TMT & Financial & Sovereign & Total \\
\hline $\begin{array}{l}\text { Optimal } \\
\text { Elastic Net }\end{array}$ & 4.2726 & 2.5729 & 2.7713 & 2.8523 & 8.2922 & 5.8820 & $\mathbf{4 . 5 3 8 0}$ \\
$\begin{array}{l}\text { Constant } \\
\text { mean }\end{array}$ & 4.2926 & 2.5783 & 2.7243 & 2.8725 & 8.3319 & 5.7668 & $\mathbf{4 . 5 4 2 4}$ \\
AR(1) & 4.3141 & 2.5795 & 2.8296 & 2.8735 & 8.2759 & 5.8282 & $\mathbf{4 . 5 5 2 8}$ \\
Ridge & 4.2950 & 2.5853 & 2.7799 & 2.8611 & 8.3120 & 5.9312 & $\mathbf{4 . 5 5 6 1}$ \\
$\begin{array}{l}\text { Constant } \\
\text { Elastic Net }\end{array}$ & 4.2826 & 2.5799 & 2.7806 & 2.8610 & 8.3226 & 5.8725 & $\mathbf{4 . 5 5 0 3}$ \\
\hline
\end{tabular}

Note: The in-sample period is $23 / 10 / 2006$ - 31/12/2014, the out-of-sample period corresponds to 02/01/2015-28/07/2017. The table shows the mean squared error (MSE) of our baseline elastic net model (first row) by sector and compares it to a number of competitor models. Our optimal elastic net model (first row) chooses optimal $\alpha$ and $\lambda$ jointly in the shrinkage and selection process. The constant mean model uses the in-sample mean of each variable as forecasts. The AR(1) model conducts forecasts based on the fitted values from a persistent process. Ridge regression applies shrinkage in the VAR with $\alpha=1$ and constant elastic net uses a fixed elastic net mixing parameter of $\alpha=0.5$ and chooses only the optimal $\lambda$ in the penalty function. 
Figure 6: CDS network before and after Lehman Brother's bankruptcy

(a) Before: September 1, 2008

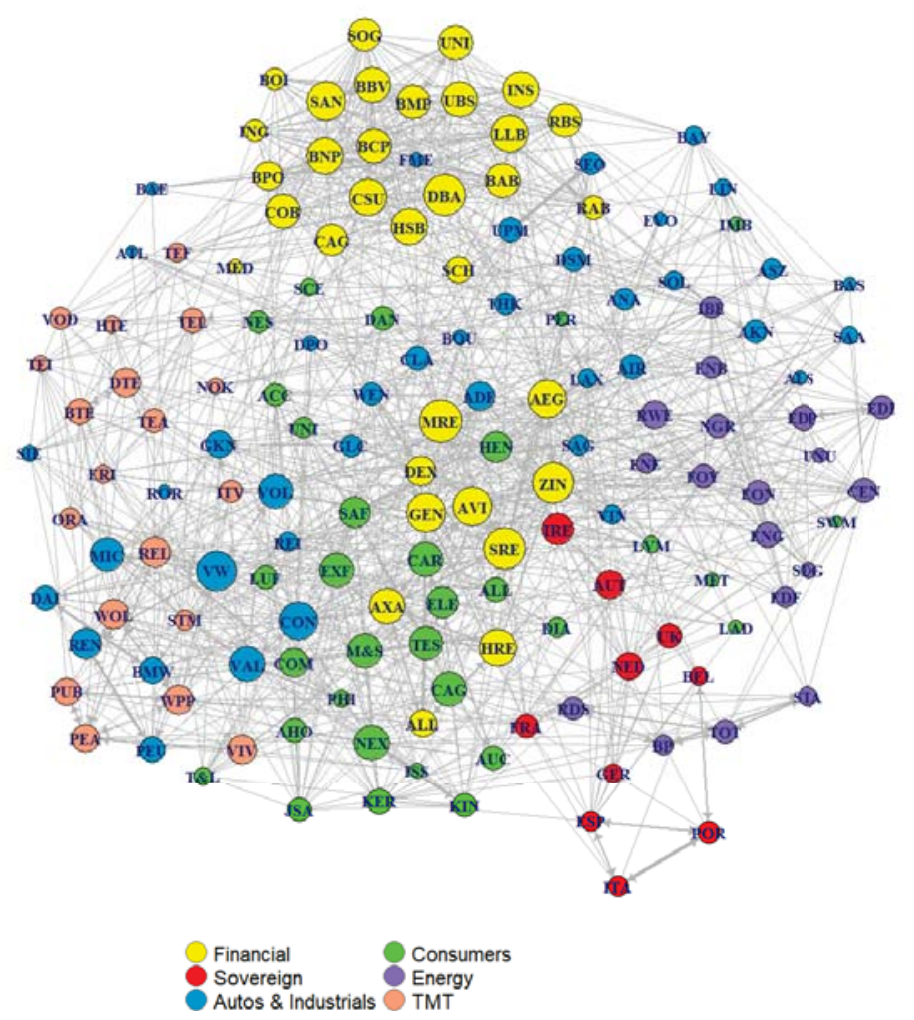

(b) After: November 6, 2008

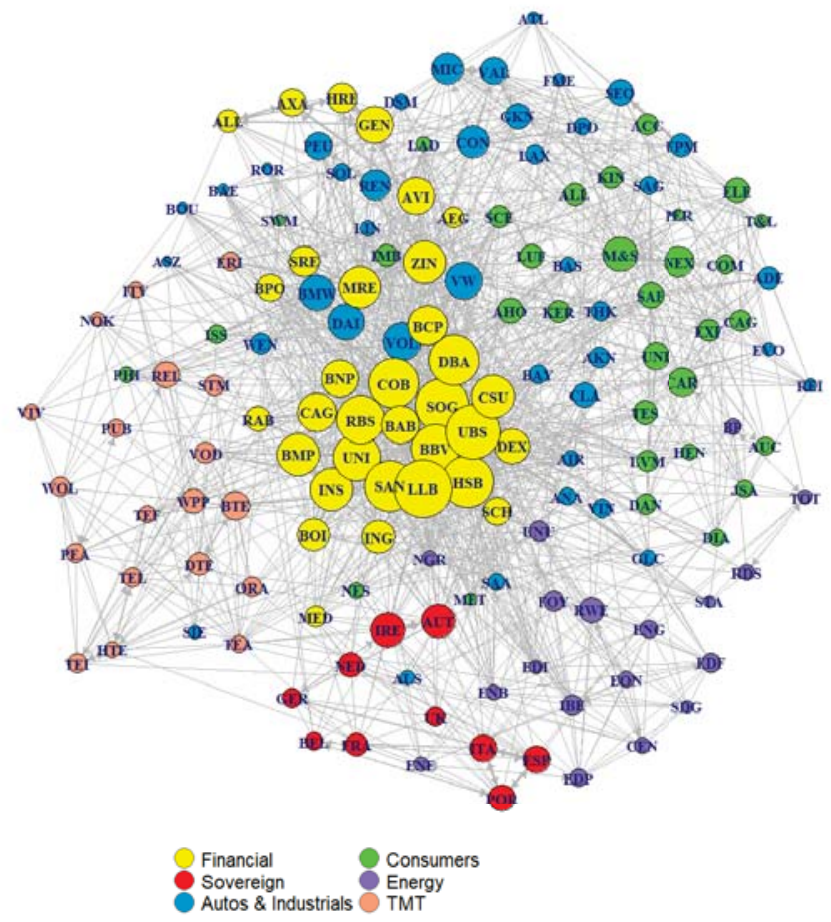


Figure 7: CDS network before and after the onset of the sovereign debt crisis

(a) Before: December 30, 2009

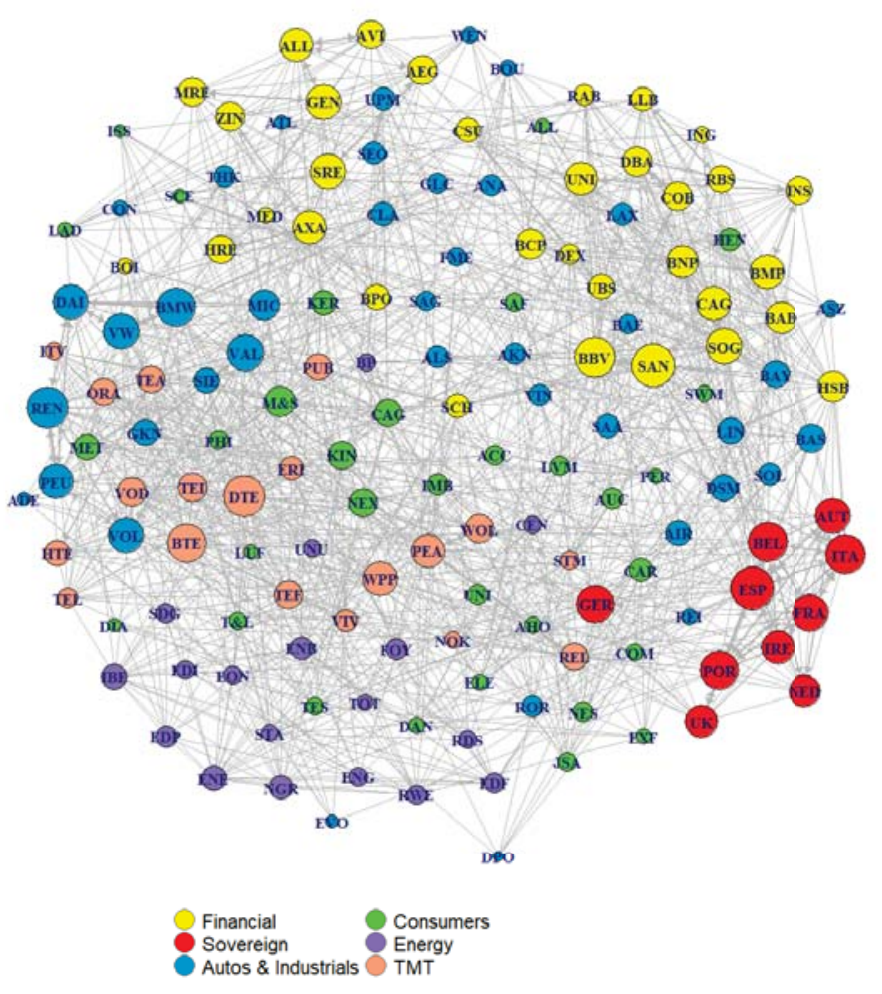

(b) After: May 5, 2010

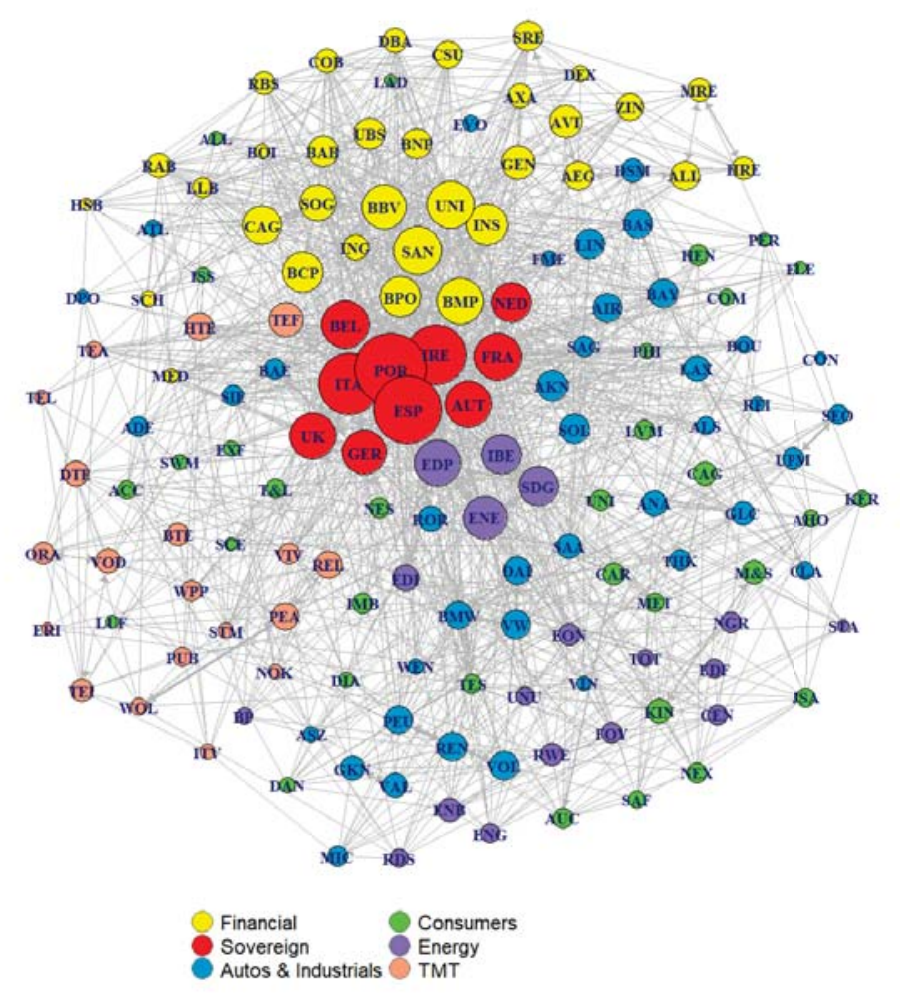


Figure 8: Dynamic system-wide connectedness

$100-$

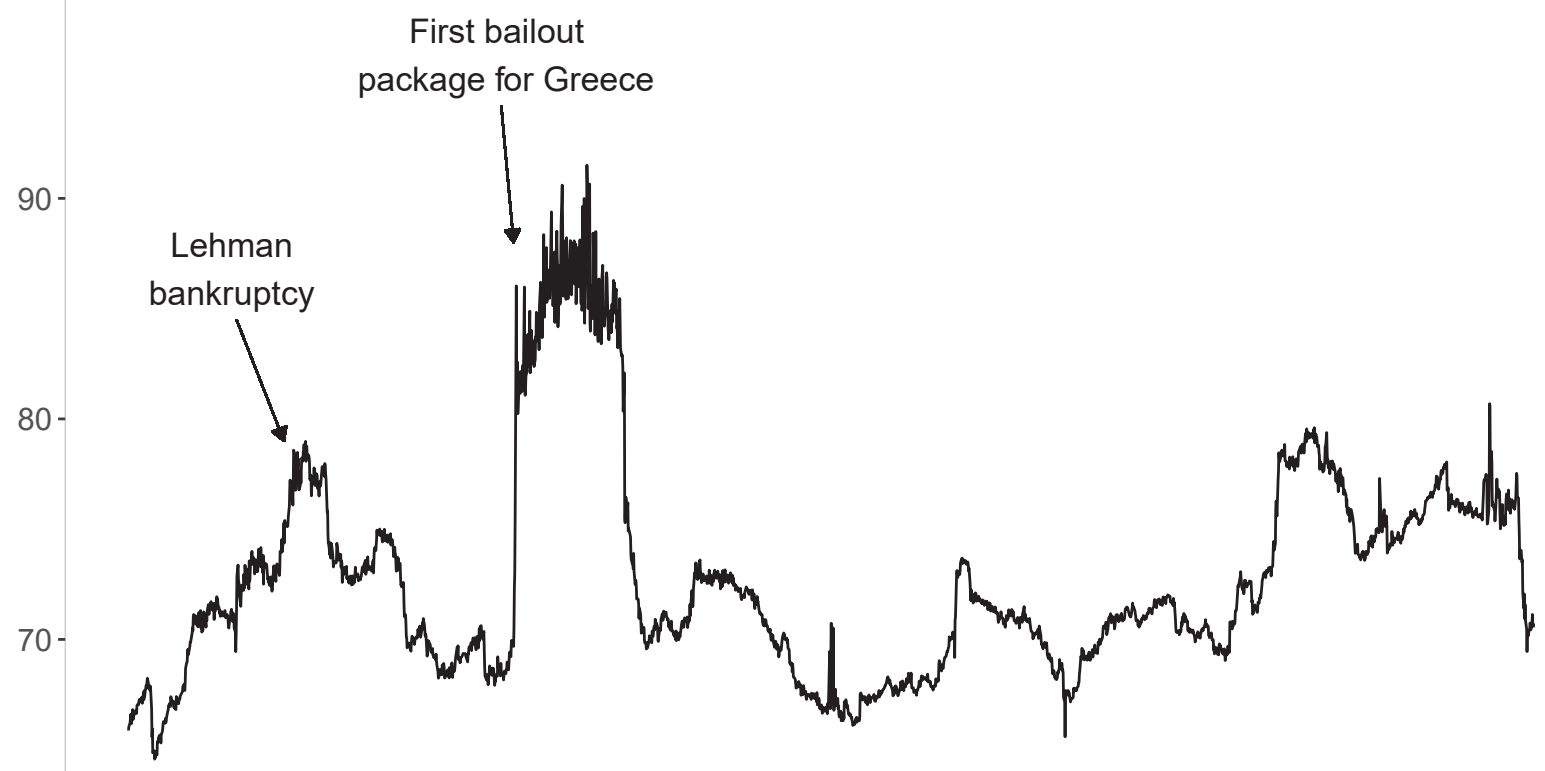

$60-$

08

$09 \quad 10 \quad 11$

1213

$14 \quad 15$

$16 \quad 17 \quad 18$

Note: The above figure shows the results from calculating time-varying parameters of the overall connectedness measure written in Eq. (7), using a rolling-window of 200 days. 
Figure 9: Dynamic cross-sectoral connectedness

\section{Financial $\rightarrow$ Non-Financial}

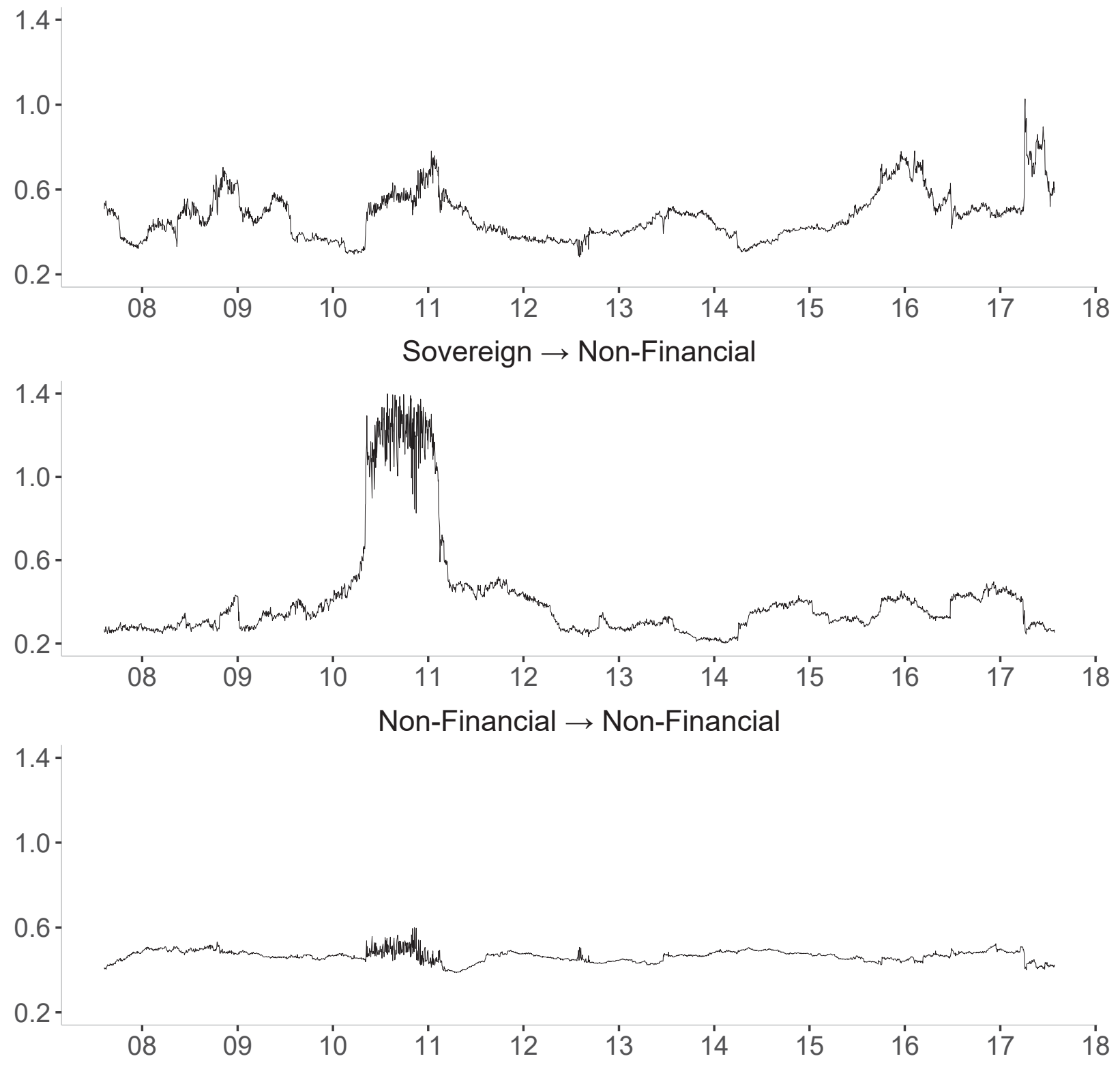

Note: The above figure shows the results from calculating time-varying parameters of the connectedness measure aggregated by sector, using a rolling-window of 200 days. Each measure is normalized by the number of entities so that the graph shows the average impact for each sector. 
Figure 10: Dynamic network connectedness across country groups

\section{Financial $\rightarrow$ Non-Financial}
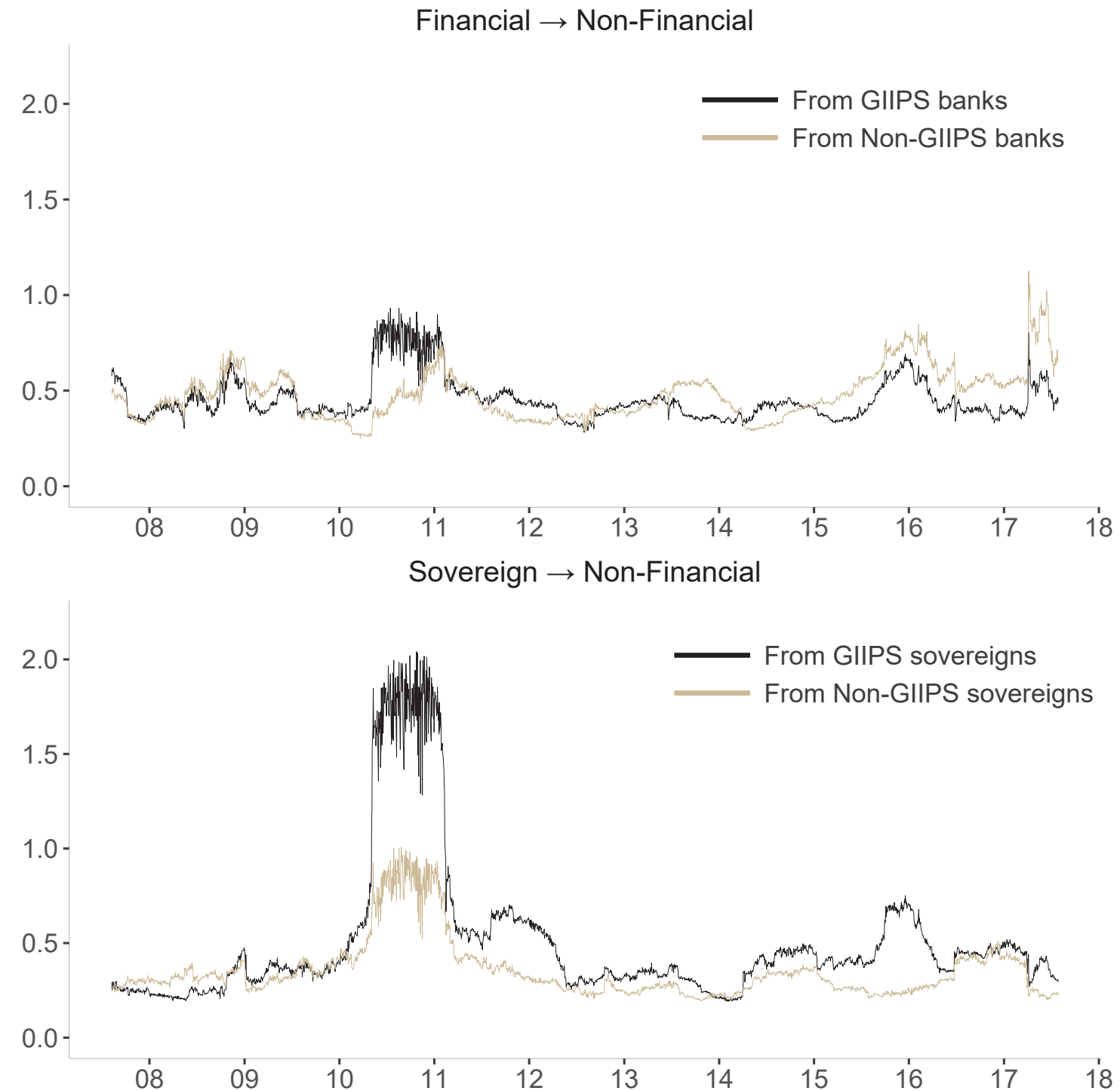

Note: The above figure shows the results from calculating time-varying parameters of the connectedness measure aggregated by country group, using a rolling-window of 200 days. (G)IIPS countries are Ireland, Italy, Portugal and Spain (Greece is exluded due to data availability). Each measure is normalized by the number of entities so that the graph shows the average impact for each group of countries. 
Figure 11: Distribution of elastic net parameters for different window sizes

(a) Mixing parameter $\alpha$

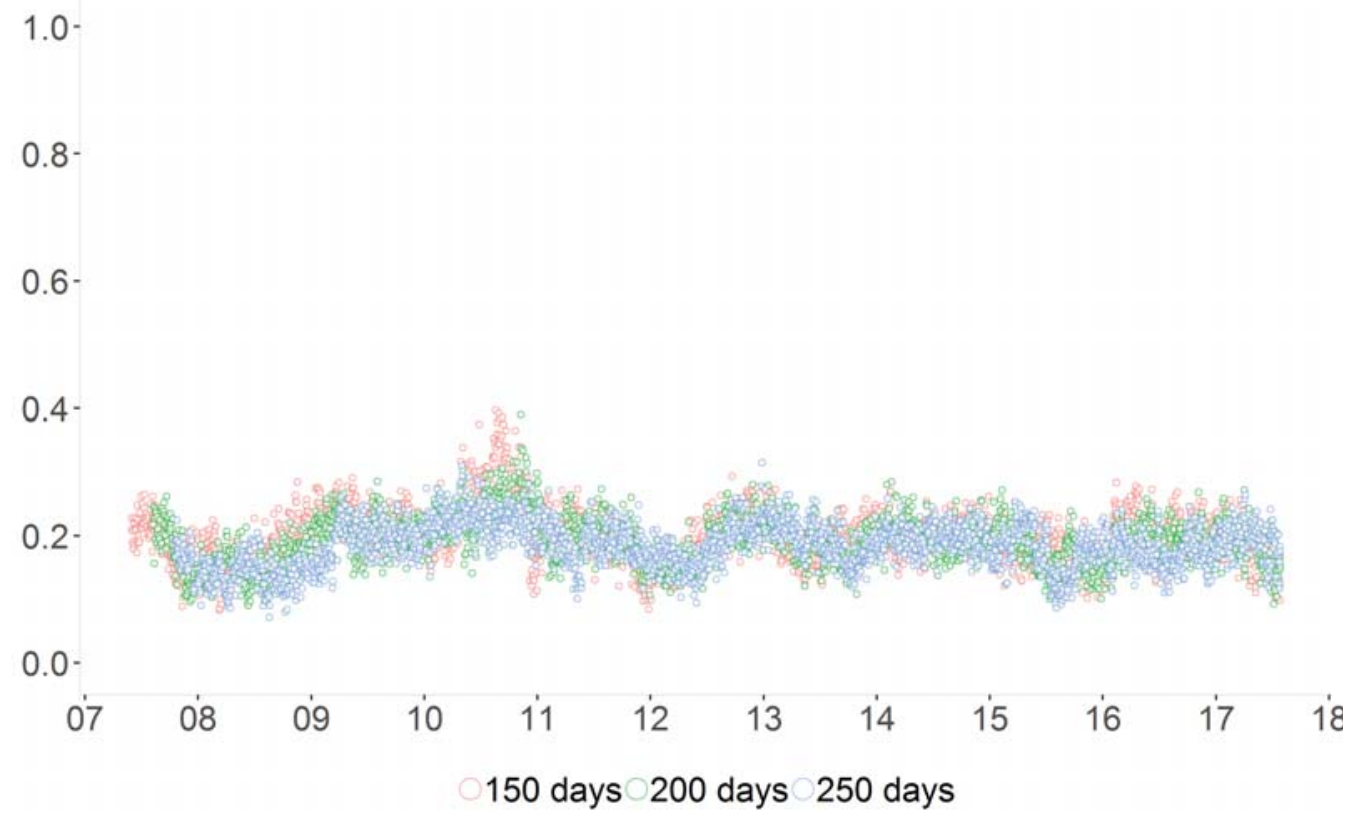

(b) Penalty tuning parameter $\lambda$

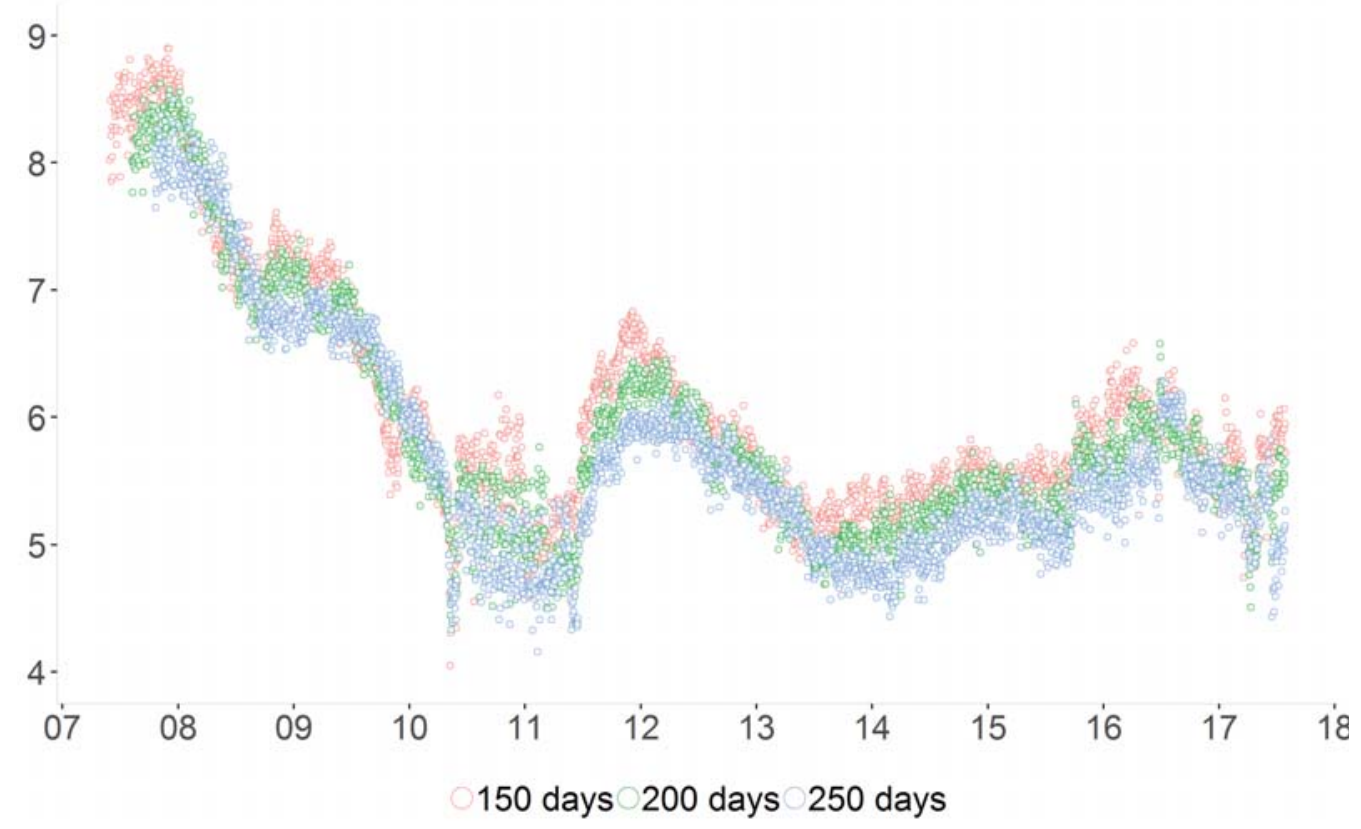

Note: Figure (a) shows the evolution of the elastic net mixing parameter $\alpha$ for the dynamic VAR framework over the sample period for different window sizes in the rolling-regression. Figure (b) depicts the corresponding values (log scale) for the penalty tuning parameter $\lambda$. Each observation for $\alpha$ and $\lambda$ represents the average value across all 152 VAR equations for each window. 
Figure 12: Dynamic Granger-causality connectedness

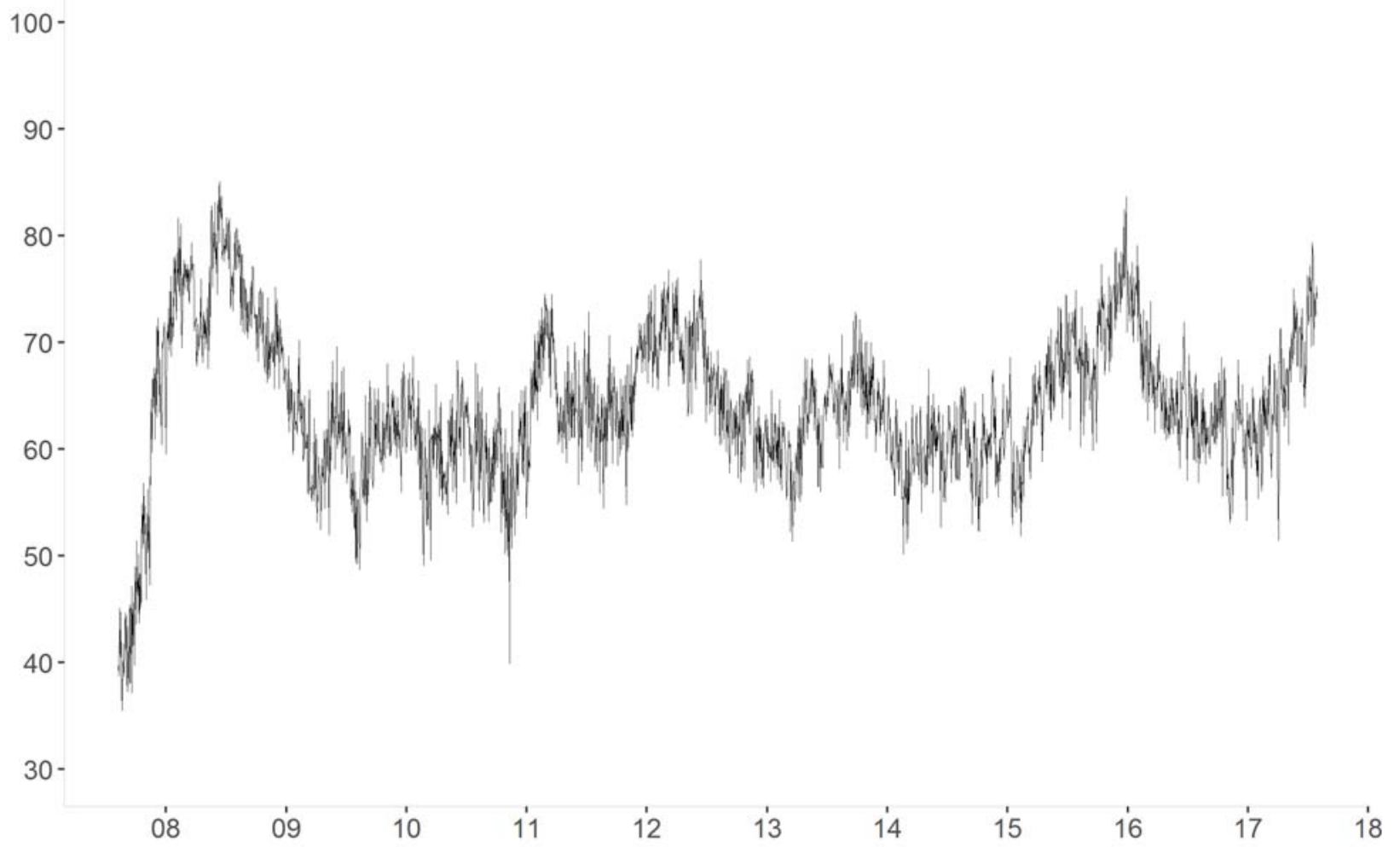

Note: The figure shows the share of Granger-causality linkages between CDS entities, i.e. it presents the share of non-zero links relative to the total number of possible links. The underlying VAR is estimated with a rolling-window of 200 days. The above figure is the analogue to the system-wide connectedness measure depicted in Figure 8 which is based on variance decompositions. 


\section{Appendix}

Table A.1: List of CDS Entities

\begin{tabular}{|c|c|c|c|c|}
\hline Entity Name & Sector & Sub-Sector & Country & Name Code \\
\hline Adecco & Non-financial & Autos \& Industrials & Switzerland & $\mathrm{ADE}$ \\
\hline Volvo & Non-financial & Autos \& Industrials & Sweden & VOL \\
\hline Akzo Nobel & Non-financial & Autos \& Industrials & Netherlands & $\mathrm{AKN}$ \\
\hline Alstom & Non-financial & Autos \& Industrials & France & ALS \\
\hline Anglo American & Non-financial & Autos \& Industrials & UK & ANA \\
\hline Astrazeneca & Non-financial & Autos \& Industrials & UK & ASZ \\
\hline Atlantia & Non-financial & Autos \& Industrials & Italy & ATL \\
\hline Bae Systems & Non-financial & Autos \& Industrials & UK & $\mathrm{BAE}$ \\
\hline BASF & Non-financial & Autos \& Industrials & Germany & BAS \\
\hline Bayer & Non-financial & Autos \& Industrials & Germany & BAY \\
\hline BMW & Non-financial & Autos \& Industrials & Germany & BMW \\
\hline Bouygues & Non-financial & Autos \& Industrials & France & $\mathrm{BOU}$ \\
\hline Clariant & Non-financial & Autos \& Industrials & Switzerland & CLA \\
\hline Saint-Gobain & Non-financial & Autos \& Industrials & France & SAG \\
\hline Michelin & Non-financial & Autos \& Industrials & Switzerland & $\mathrm{MIC}$ \\
\hline Continental & Non-financial & Autos \& Industrials & Germany & $\mathrm{CON}$ \\
\hline Daimler & Non-financial & Autos \& Industrials & Germany & DAI \\
\hline Deutsche Post & Non-financial & Autos \& Industrials & Germany & $\mathrm{DPO}$ \\
\hline Evonik & Non-financial & Autos \& Industrials & Germany & $\mathrm{EVO}$ \\
\hline Finmeccanica & Non-financial & Autos \& Industrials & Italy & FME \\
\hline GKN Holding & Non-financial & Autos \& Industrials & UK & GKN \\
\hline Glencore & Non-financial & Autos \& Industrials & Switzerland & GLC \\
\hline Koninklijke DSM & Non-financial & Autos \& Industrials & Netherlands & DSM \\
\hline Air Liquide & Non-financial & Autos \& Industrials & France & AIR \\
\hline Lanxess & Non-financial & Autos \& Industrials & Germany & LAX \\
\hline Linde & Non-financial & Autos \& Industrials & Germany & LIN \\
\hline Peugeot & Non-financial & Autos \& Industrials & France & $\mathrm{PEU}$ \\
\hline Renault & Non-financial & Autos \& Industrials & France & REN \\
\hline Rentokil Initial & Non-financial & Autos \& Industrials & UK & REI \\
\hline Rolls-Royce & Non-financial & Autos \& Industrials & UK & ROR \\
\hline Sanofi-Aventis & Non-financial & Autos \& Industrials & France & SAA \\
\hline Siemens & Non-financial & Autos \& Industrials & Germany & SIE \\
\hline Stora Enso Oyj & Non-financial & Autos \& Industrials & Finland & SEO \\
\hline Solvay & Non-financial & Autos \& Industrials & Belgium & SOL \\
\hline ThyssenKrupp & Non-financial & Autos \& Industrials & Germany & THK \\
\hline UPM-Kymmene Oyj & Non-financial & Autos \& Industrials & Finland & UPM \\
\hline Valeo & Non-financial & Autos \& Industrials & France & VAL \\
\hline Vinci & Non-financial & Autos \& Industrials & France & VIN \\
\hline Volkswagen & Non-financial & Autos \& Industrials & Germany & VOL \\
\hline Wendel & Non-financial & Autos \& Industrials & France & WEN \\
\hline Accor & Non-financial & Consumers & France & $\mathrm{ACC}$ \\
\hline Electrolux & Non-financial & Consumers & Sweden & ELE \\
\hline Auchan & Non-financial & Consumers & France & AUC \\
\hline Alliance Boots & Non-financial & Consumers & UK & ALL \\
\hline Carrefour & Non-financial & Consumers & France & CAR \\
\hline Casino Guichard & Non-financial & Consumers & France & CAG \\
\hline Compass & Non-financial & Consumers & UK & $\mathrm{COM}$ \\
\hline Danone & Non-financial & Consumers & France & DAN \\
\hline Lufthansa & Non-financial & Consumers & Germany & LUF \\
\hline Diageo & Non-financial & Consumers & UK & DIA \\
\hline Experian Finance & Non-financial & Consumers & UK & $\mathrm{EXF}$ \\
\hline
\end{tabular}


(Table A.1 continued)

\begin{tabular}{|c|c|c|c|c|}
\hline Entity Name & Sector & Sub-Sector & Country & Name Code \\
\hline Henkel & Non-financial & Consumers & Germany & HEN \\
\hline Ladbrokes & Non-financial & Consumers & UK & LAD \\
\hline Imperial Brands & Non-financial & Consumers & UK & IMB \\
\hline ISS Global & Non-financial & Consumers & Denmark & ISS \\
\hline J Sainsbury & Non-financial & Consumers & UK & JSA \\
\hline Kering & Non-financial & Consumers & France & KER \\
\hline Kingfisher & Non-financial & Consumers & UK & KIN \\
\hline Koninklijke Ahold Delhaize & Non-financial & Consumers & Netherlands & $\mathrm{AHO}$ \\
\hline Koninklijke Philips & Non-financial & Consumers & Netherlands & PHI \\
\hline LVMH & Non-financial & Consumers & France & LVM \\
\hline Marks \& Spencer & Non-financial & Consumers & UK & M\&S \\
\hline Metro & Non-financial & Consumers & Germany & MET \\
\hline Nestlé & Non-financial & Consumers & Switzerland & NES \\
\hline Next & Non-financial & Consumers & UK & NEX \\
\hline PernodRicard & Non-financial & Consumers & France & PER \\
\hline Safeway & Non-financial & Consumers & UK & SAF \\
\hline Svenska Cellulosa & Non-financial & Consumers & Sweden & SCE \\
\hline Swedish Match & Non-financial & Consumers & Sweden & SWM \\
\hline Tate \& Lyle & Non-financial & Consumers & UK & $\mathrm{T} \& \mathrm{~L}$ \\
\hline Tesco & Non-financial & Consumers & UK & TES \\
\hline Unilever & Non-financial & Consumers & UK & UNI \\
\hline $\mathrm{BP}$ & Non-financial & Energy & UK & $\mathrm{BP}$ \\
\hline Centrica & Non-financial & Energy & UK & CEN \\
\hline EON & Non-financial & Energy & Germany & EON \\
\hline Edison & Non-financial & Energy & Italy & EDI \\
\hline Energias de Portugal & Non-financial & Energy & Portugal & EDP \\
\hline Electricité de France & Non-financial & Energy & France & $\mathrm{EDF}$ \\
\hline ENBW & Non-financial & Energy & Germany & ENB \\
\hline ENEL & Non-financial & Energy & Italy & ENE \\
\hline ENGIE & Non-financial & Energy & France & ENG \\
\hline Fortum OYJ & Non-financial & Energy & Finland & FOY \\
\hline Gas Natural SDG & Non-financial & Energy & Spain & SDG \\
\hline Iberdrola & Non-financial & Energy & Spain & IBE \\
\hline National Grid & Non-financial & Energy & UK & NGR \\
\hline Royal Dutch Shell & Non-financial & Energy & Netherlands & RDS \\
\hline RWE & Non-financial & Energy & Germany & RWE \\
\hline Statoil & Non-financial & Energy & Norway & STA \\
\hline Total & Non-financial & Energy & France & TOT \\
\hline United Utilities & Non-financial & Energy & UK & UNU \\
\hline British Telecom & Non-financial & TMT & UK & BTE \\
\hline Deutsche Telekom & Non-financial & TMT & Germany & DTE \\
\hline Hellenic Telecom & Non-financial & TMT & Greece & HTE \\
\hline ITV & Non-financial & TMT & UK & ITV \\
\hline Nokia & Non-financial & TMT & Finland & NOK \\
\hline Orange & Non-financial & TMT & France & ORA \\
\hline Pearson & Non-financial & TMT & UK & PEA \\
\hline Publicis & Non-financial & TMT & France & PUB \\
\hline Relx & Non-financial & TMT & UK & REL \\
\hline St Microelectronics & Non-financial & TMT & Switzerland & STM \\
\hline Ericsson & Non-financial & TMT & Sweden & ERI \\
\hline Telefonica & Non-financial & TMT & Spain & TEF \\
\hline
\end{tabular}


(Table A.1 continued)

\begin{tabular}{|c|c|c|c|c|}
\hline Entity Name & Sector & Sub-Sector & Country & Name Code \\
\hline Telekom Austria & Non-financial & TMT & Austria & TEA \\
\hline Telenor & Non-financial & TMT & Norway & TEL \\
\hline Telia & Non-financial & TMT & Sweden & TEI \\
\hline Vivendi & Non-financial & TMT & France & VIV \\
\hline Vodafone & Non-financial & TMT & UK & VOD \\
\hline Wolters & Non-financial & TMT & Netherlands & WOL \\
\hline WPP & Non-financial & TMT & UK & WPP \\
\hline Aegon & \multicolumn{2}{|c|}{$\begin{array}{ll}\text { Financial } \\
\end{array}$} & Netherlands & AEG \\
\hline Allianz & \multicolumn{2}{|c|}{ Financial } & Germany & ALL \\
\hline Generali & \multicolumn{2}{|c|}{ Financial } & Italy & GEN \\
\hline Aviva & \multicolumn{2}{|c|}{ Financial } & UK & AVI \\
\hline AXA & \multicolumn{2}{|c|}{ Financial } & France & AXA \\
\hline Hannover Rueck & \multicolumn{2}{|c|}{ Financial } & Germany & HRE \\
\hline Munich RE & \multicolumn{2}{|c|}{ Financial } & Germany & MRE \\
\hline Swiss RE & \multicolumn{2}{|c|}{ Financial } & Switzerland & SRE \\
\hline Zurich Insurance & \multicolumn{2}{|c|}{ Financial } & Switzerland & ZIN \\
\hline Dexia & \multicolumn{2}{|c|}{ Financial } & Belgium & DEX \\
\hline BNP Paribas & \multicolumn{2}{|c|}{ Financial } & France & BNP \\
\hline Crédit Agricole & \multicolumn{2}{|c|}{ Financial } & France & CAG \\
\hline Société Générale & \multicolumn{2}{|c|}{ Financial } & France & SOG \\
\hline Deutsche Bank & \multicolumn{2}{|c|}{ Financial } & Germany & DBA \\
\hline Commerzbank & \multicolumn{2}{|c|}{ Financial } & Germany & $\mathrm{COB}$ \\
\hline Bank of Ireland & \multicolumn{2}{|c|}{ Financial } & Ireland & BOI \\
\hline Intesa Sanpaolo & \multicolumn{2}{|c|}{ Financial } & Italy & INS \\
\hline Banca Monte Di Paschi & \multicolumn{2}{|c|}{ Financial } & Italy & BMP \\
\hline Banca Popolare & \multicolumn{2}{|c|}{ Financial } & Italy & $\mathrm{BPO}$ \\
\hline Unicredit & \multicolumn{2}{|c|}{ Financial } & Italy & UNI \\
\hline Mediobanca & \multicolumn{2}{|c|}{ Financial } & Italy & MED \\
\hline ING & & & Netherlands & ING \\
\hline Rabobank & & & Netherlands & RAB \\
\hline Banco Comercial Port. & & & Portugal & $\mathrm{BCP}$ \\
\hline Santander & & & Spain & SAN \\
\hline BBVA & & & Spain & BBV \\
\hline Royal Bank of Scot. & & & UK & RBS \\
\hline HSBC Bank & & & UK & HSB \\
\hline Barclays Bank & & & UK & BAB \\
\hline Lloyds Bank & & & UK & LLB \\
\hline Standard Chartered & & & UK & $\mathrm{SCH}$ \\
\hline UBS & & & Switzerland & UBS \\
\hline Credit Suisse & & & Switzerland & $\mathrm{CSU}$ \\
\hline Austria & & & Austria & $\overline{\text { AUT }}$ \\
\hline Belgium & & & Belgium & BEL \\
\hline France & & ign & France & FRA \\
\hline Germany & & ign & Germany & GER \\
\hline Ireland & & ign & Ireland & IRE \\
\hline Italy & & & Italy & ITA \\
\hline Netherlands & & ign & Netherlands & NED \\
\hline Portugal & & ign & Portugal & POR \\
\hline Spain & & ign & Spain & ESP \\
\hline UK & & ign & Spain & UK \\
\hline
\end{tabular}




\section{Online Appendix ${ }^{1}$}

\section{A. Determining the number of common factors}

Hallin and Liška (2007) propose a consistent information criterion for determining the number of $q$ common dynamic shocks in Forni et al.'s (2000) generalized dynamic factor model. The criterion builds on the $(n, T)$-asymptotic properties of the eigenvalues for the spectral density matrix of the observable variables $Y_{n t}$. The spectral density matrix is denoted by $\Sigma_{n}(\theta)$, where $\theta \in[-\pi, \pi]$, and its corresponding eigenvalues in decreasing order of magnitude are denoted by $\kappa_{n 1}(\theta), \ldots, \kappa_{n n}(\theta)$. As $n \rightarrow \infty$ it can be shown that the projection $X_{i t}^{(n)}$ of $Y_{i t}$ onto the space spanned by $\boldsymbol{\Sigma}_{n}(\theta)$ 's first $q$ dynamic principal components provides a consistent reconstruction of $X_{i t}$, where the number $q$ is equivalent to the number of diverging eigenvalues of $\boldsymbol{\Sigma}_{n}(\theta)$. As illustrated by Hallin and Liška (2007) the $q$ dynamic principal components and the $X_{i t}^{(n)}$ 's are the solutions to an optimization problem in which the expected mean of squared residuals is minimized.

Accordingly, Hallin and Liška (2007) propose that the estimated number of factors, for given $(n, T)$ and a maximum number of common factors $q_{\max }$, is determined by minimizing the following information criterion:

$$
I C_{2 ; n}^{T}(k)=\log \left[\frac{1}{n} \sum_{i=k+1}^{n} \frac{1}{2 M_{T}+1} \sum_{l=-M_{T}}^{M_{T}} \kappa_{n i}^{T}\left(\theta_{l}\right)\right]+k p(n, T),
$$

where $0 \leq k \leq q_{\max }$.

$M_{T}>0$ is a truncation parameter and $p(n, T)$ is an appropriate penalty function whose conditions and properties are discussed in detail by Hallin and Liška (2007). Provided that $p(n, T)$ is an appropriate penalty function, then multiplying the penalty with an arbitrary positive real constant $c$, i.e. $c p(n, T)$, is also appropriate. The uncertainty regarding the choice of $c$ is exploited by Hallin and Liška (2007) to derive a practical guide for the selection of $q$, which is based on a mapping of $c \rightarrow q_{c, n}^{T}$ and $c \rightarrow S_{c}$ in a joint plot. $q_{c, n}^{T}$ denotes the number of factors resulting from applying the $I C_{2}$ criterion in Eq. (OA.1) and $S_{c}$ captures

\footnotetext{
${ }^{1}$ Not for publication.
} 
the variability among the $J$ values of $q_{c ; n_{j}}^{T_{j}}, j=1, \ldots, J$ in a sample with fixed $n$ and $T$ and allows for an assessment of the stability of the factors for a given $c$.

Figure OA.1: Hallin and Liška (2007) $I C_{2}$ criterion

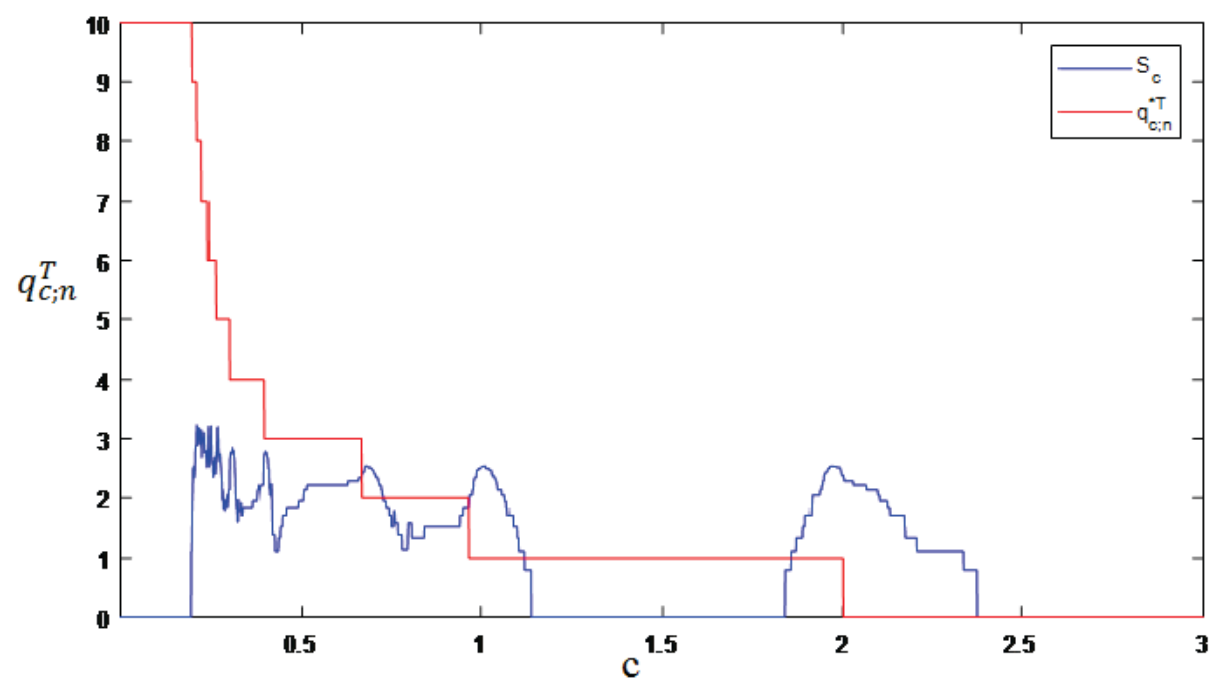

Note: The figure shows the joint mapping of $c \rightarrow q_{c, n}^{T}$ and $c \rightarrow S_{c}$ for the panel of 152 CDS returns. $q_{c, n}^{T}$ is derived from applying the $I C_{2}$ criterion as shown in (OA.1) using a penalty function of $p(n, T)=\left(M_{T}^{-2}+M_{T}^{0.5} T^{-0.5}+\right.$ $\left.n^{-1}\right) \log \left(\min \left[n, M_{T}^{2}, M_{T}^{-0.5} T^{0.5}\right]\right)$.

Figure OA.1 depicts the joint mapping for our sample of 152 CDS series. As can be seen the values for $S_{c}$ are 0 in several intervals of $c$, which are called "stability intervals" in the terminology of Hallin and Liška (2007), while the values for $S_{c}$ fluctuate heavily in other regions of $c$ (hence they are called "instability intervals"). For values of $c$ close to 0 , the first "stability interval" typically yields the maximum possible numbers of common factors $\hat{q}=q_{\max }$. Since low values of $c$ are associated with severe underpenalization Hallin and Liška (2007) propose to choose the number of factors $\hat{q}=q_{\hat{c}, n}^{T}$ by considering the $c \rightarrow S_{c}$ mapping where $\hat{c}$ belongs to the second "stability interval". In Figure OA.1 this is the case for the interval $c=[1.15,1.84]$ which corresponds to $q=1$, hence the criterion clearly identifies one common factor in our sample and higher-order factor model specifications are not supported. 


\section{B. Dataset of CDS spreads}

Table OA.1: Summary statistics of CDS data by country

\begin{tabular}{|c|c|c|c|c|c|c|c|c|c|}
\hline \multicolumn{10}{|c|}{ Panel A: CDS non-financial corporations } \\
\hline \multirow[b]{2}{*}{ Country } & \multirow[b]{2}{*}{ Entities } & \multicolumn{4}{|c|}{ Raw returns } & \multicolumn{4}{|c|}{ Idiosyncratic returns } \\
\hline & & Mean & $\begin{array}{l}\text { Std. } \\
\text { dev. }\end{array}$ & Min & Max & Mean & $\begin{array}{l}\text { Std. } \\
\text { dev. }\end{array}$ & Min & Max \\
\hline Austria & 1 & 0.00 & 3.12 & -24.76 & 25.16 & 0.00 & 2.03 & -12.76 & 18.34 \\
\hline Belgium & 1 & 0.04 & 3.33 & -24.99 & 27.46 & 0.00 & 2.20 & -13.46 & 26.59 \\
\hline Denmark & 1 & -0.04 & 3.65 & -83.40 & 38.09 & 0.00 & 3.25 & -82.86 & 32.30 \\
\hline Finland & 4 & 0.04 & 3.43 & -83.81 & 37.77 & 0.00 & 2.61 & -84.21 & 33.87 \\
\hline France & 24 & 0.02 & 3.34 & -58.90 & 60.05 & 0.00 & 2.32 & -59.10 & 56.89 \\
\hline Germany & 19 & 0.02 & 3.41 & -33.47 & 103.03 & 0.00 & 2.36 & -32.10 & 104.47 \\
\hline Greece & 1 & 0.06 & 4.68 & -33.14 & 44.11 & 0.00 & 3.69 & -26.79 & 44.37 \\
\hline Italy & 4 & 0.05 & 3.71 & -53.65 & 33.74 & 0.00 & 2.73 & -52.62 & 31.62 \\
\hline Netherlands & 6 & 3.29 & 0.032 & -77.98 & 80.75 & 0.00 & 2.41 & -80.11 & 78.10 \\
\hline Norway & 2 & 0.02 & 3.14 & -25.62 & 29.90 & 0.00 & 2.36 & -16.90 & 26.71 \\
\hline Portugal & 1 & 0.06 & 4.13 & -39.00 & 29.34 & 0.00 & 2.76 & -29.63 & 19.28 \\
\hline Spain & 3 & 0.03 & 4.03 & -39.99 & 30.53 & 0.00 & 2.64 & -19.22 & 30.17 \\
\hline Sweden & 6 & 0.02 & 2.96 & -28.86 & 51.84 & 0.00 & 2.11 & -24.43 & 51.71 \\
\hline Switzerland & 6 & 0.02 & 3.57 & -44.11 & 44.11 & 0.00 & 2.60 & -36.85 & 38.27 \\
\hline UK & 30 & 0.03 & 3.39 & -127.01 & 140.46 & 0.00 & 2.56 & -129.97 & 139.87 \\
\hline \multicolumn{10}{|c|}{ Panel B: CDS financial institutions } \\
\hline & & \multicolumn{4}{|c|}{ Raw returns } & \multicolumn{4}{|c|}{ Idiosyncratic returns } \\
\hline Country & Entities & Mean & $\begin{array}{l}\text { Std. } \\
\text { dev. }\end{array}$ & Min & Max & Mean & $\begin{array}{l}\text { Std. } \\
\text { dev. }\end{array}$ & Min & Max \\
\hline Belgium & 1 & 0.11 & 4.47 & -35.06 & 86.61 & 0.00 & 4.23 & -34.17 & 86.82 \\
\hline France & 4 & 0.05 & 4.80 & -43.96 & 62.68 & 0.00 & 3.24 & -22.58 & 42.14 \\
\hline Germany & 5 & 0.05 & 4.96 & -47.63 & 61.34 & 0.00 & 3.32 & -37.74 & 40.60 \\
\hline Ireland & 1 & 0.08 & 5.84 & -86.90 & 60.45 & 0.00 & 5.61 & -86.73 & 58.79 \\
\hline Italy & 6 & 0.08 & 4.76 & -53.99 & 75.37 & 0.00 & 3.38 & -53.62 & 55.22 \\
\hline Netherlands & 3 & 0.07 & 4.44 & -38.22 & 67.65 & 0.00 & 3.38 & -32.84 & 62.16 \\
\hline Portugal & 1 & 0.10 & 4.31 & -35.41 & 40.67 & 0.00 & 3.40 & -17.93 & 47.57 \\
\hline Spain & 2 & 0.05 & 4.79 & -45.72 & 32.54 & 0.00 & 3.07 & -16.60 & 20.17 \\
\hline Switzerland & 4 & 0.05 & 4.51 & -41.03 & 56.25 & 0.00 & 3.06 & -33.50 & 30.57 \\
\hline UK & 6 & 0.06 & 4.80 & -70.69 & 65.79 & 0.00 & 3.44 & -61.27 & 56.97 \\
\hline \multicolumn{10}{|c|}{ Panel C: CDS sovereigns } \\
\hline & & \multicolumn{4}{|c|}{ Raw returns } & \multicolumn{4}{|c|}{ Idiosyncratic returns } \\
\hline Country & Entities & Mean & $\begin{array}{l}\text { Std. } \\
\text { dev. }\end{array}$ & Min & $\operatorname{Max}$ & Mean & $\begin{array}{l}\text { Std. } \\
\text { dev. }\end{array}$ & Min & $\operatorname{Max}$ \\
\hline Austria & 1 & 0.09 & 10.42 & -200.14 & 153.14 & 0.01 & 10.17 & -197.03 & 153.23 \\
\hline Belgium & 1 & 0.06 & 4.46 & -28.76 & 30.59 & 0.00 & 3.93 & -28.04 & 31.58 \\
\hline France & 1 & 0.07 & 10.17 & -200.14 & 153.14 & 0.00 & 9.97 & -197.37 & 153.24 \\
\hline Germany & 1 & 0.07 & 9.45 & -133.50 & 154.04 & 0.01 & 9.27 & -133.93 & 154.23 \\
\hline Ireland & 1 & 0.08 & 16.40 & -208.63 & 207.18 & 0.00 & 16.33 & -208.23 & 207.81 \\
\hline Italy & 1 & 0.07 & 4.21 & -36.27 & 33.12 & 0.00 & 3.55 & -33.11 & 25.59 \\
\hline Netherlands & 1 & 0.10 & 6.25 & -65.92 & 65.92 & 0.00 & 6.12 & -65.35 & 69.46 \\
\hline Portugal & 1 & 0.11 & 4.60 & -51.27 & 27.99 & 0.00 & 4.05 & -34.40 & 25.59 \\
\hline Spain & 1 & 0.06 & 5.24 & -57.05 & 57.05 & 0.00 & 4.87 & -58.66 & 56.74 \\
\hline UK & 1 & 0.09 & 4.44 & -40.54 & 93.60 & 0.00 & 4.21 & -40.90 & 92.17 \\
\hline
\end{tabular}

Note: The table shows descriptive statistics of CDS raw and idiosyncratic returns by country and sector. Raw CDS returns have been demeaned prior to computation of the common and idiosyncratic returns. 


\section{Additional results for cross-sectoral connectedness}

Figure OA.2: Dynamic cross-sectoral connectedness, net contribution
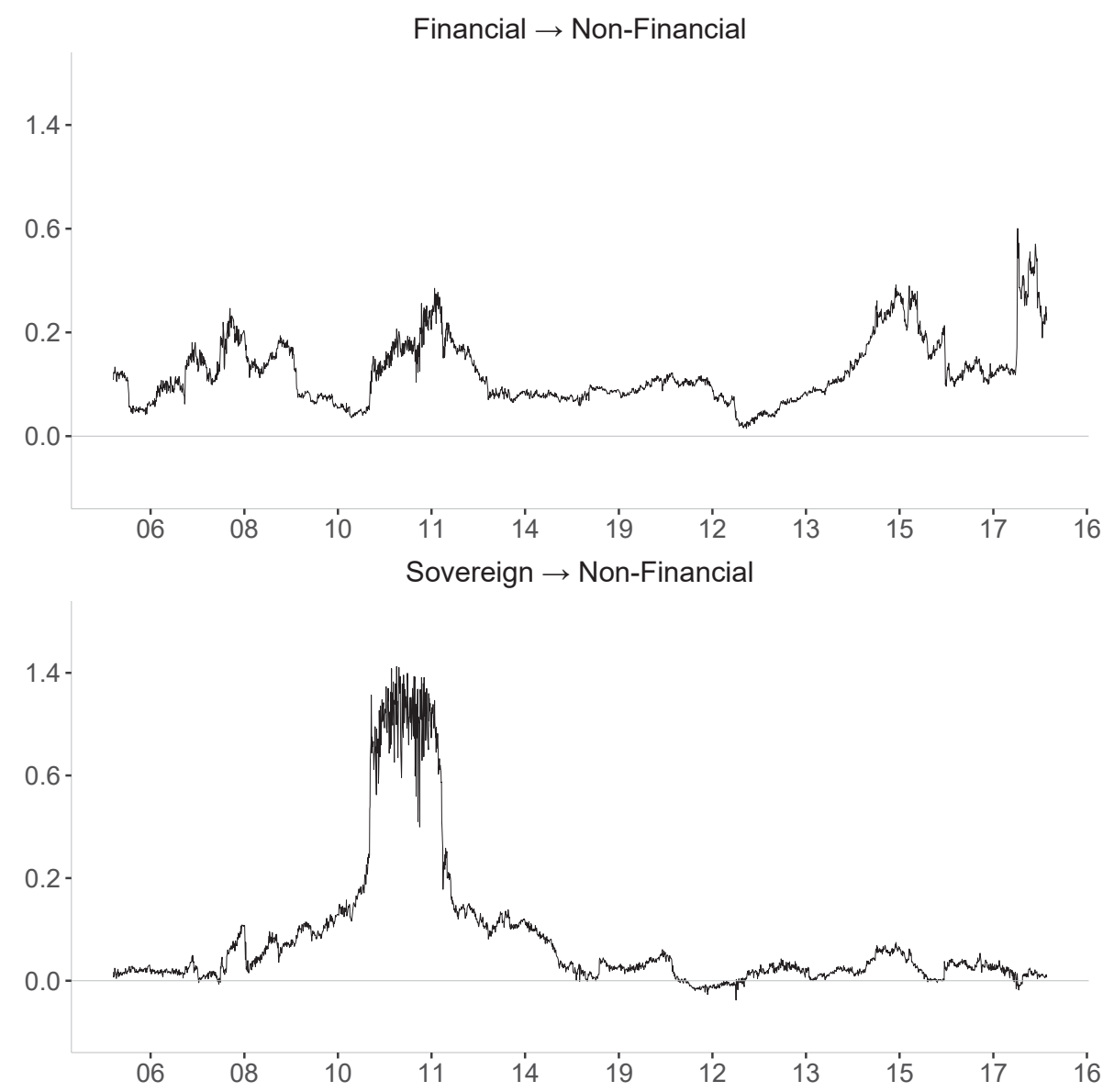

Note: The above figure shows aggregate net contribution of the financial and sovereign sector, respectively, to the non-financial sector in a dynamic framework (rolling window of 200 days). Net contribution of the financial sector is "aggregate connectedness from financial institutions to non-financial corporations" minus "aggregate connectedness from non-financial corporations to financial institutions". Net contribution of the sovereign sector is "aggregate connectedness from sovereigns to non-financial corporations" minus "aggregate connectedness from non-financial corporations to sovereigns". Each measure is normalized by the number of entities so that the graph shows the average impact for each sector. 
Figure OA.3: Dynamic cross-sectoral connectedness, sub-sectors

Financial $\rightarrow$ Autos \& Industrials

$1.4-$

1.0

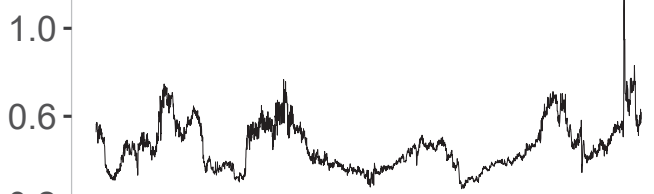

$0.2-$ $09 \quad 11 \quad 13 \quad 15 \quad 17$

Financial $\rightarrow$ Consumers
Sovereign $\rightarrow$ Autos \& Industrials

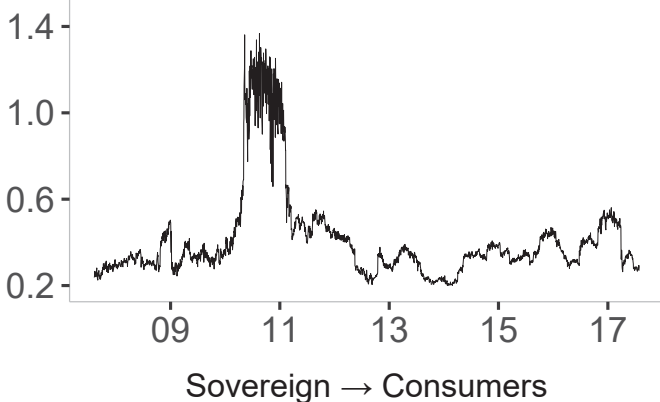

$1.4-$

$1.4-$

$1.0-$

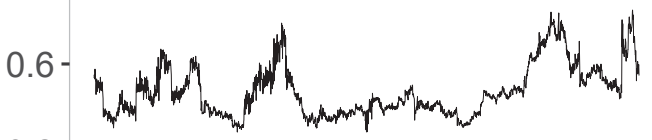

$0.2-$

$\begin{array}{lllll}09 & 11 & 13 & 15 & 17\end{array}$

Financial $\rightarrow$ Energy

$1.4-$

$1.4-$

2

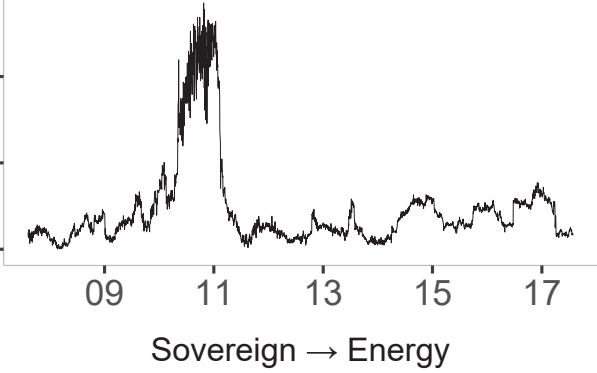

$1.0-$

1.0

0.6 -

0.2

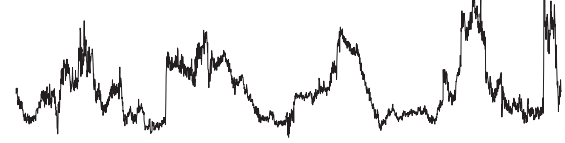

$\begin{array}{lllll}0 & 11 & 13 & 15 & 17\end{array}$

Financial $\rightarrow$ TMT

$1.4-$

$0.6-$

$0.2-$

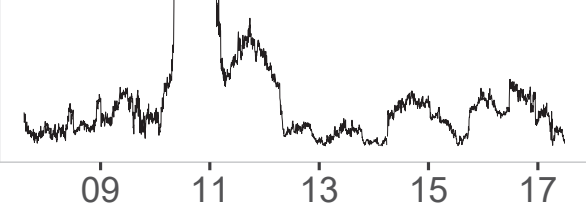

Sovereign $\rightarrow$ TMT

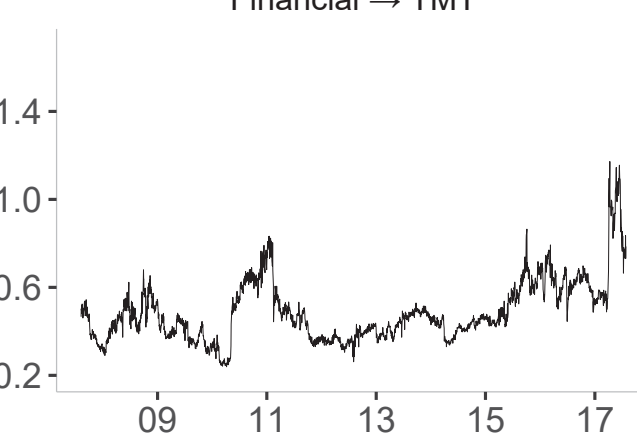

1.4

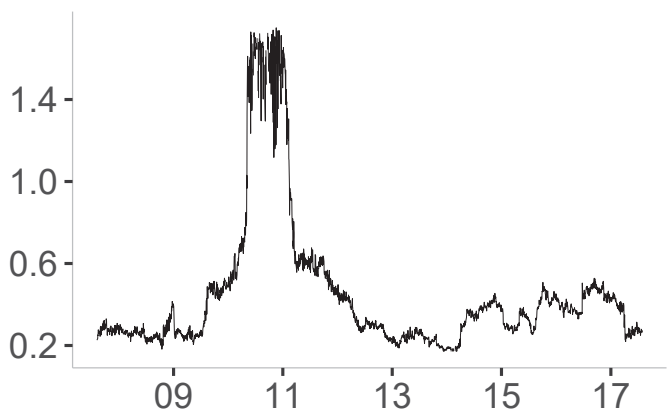

Note: The above figure shows the results from calculating time-varying parameters of the connectedness measure aggregated by sub-sectors, using a rolling-window of 200 days. Each measure is normalized by the number of entities so that the graph shows the average impact for each sub-sector. 
Figure OA.4: Static Granger-causality cross-sectoral network connectedness 1.00

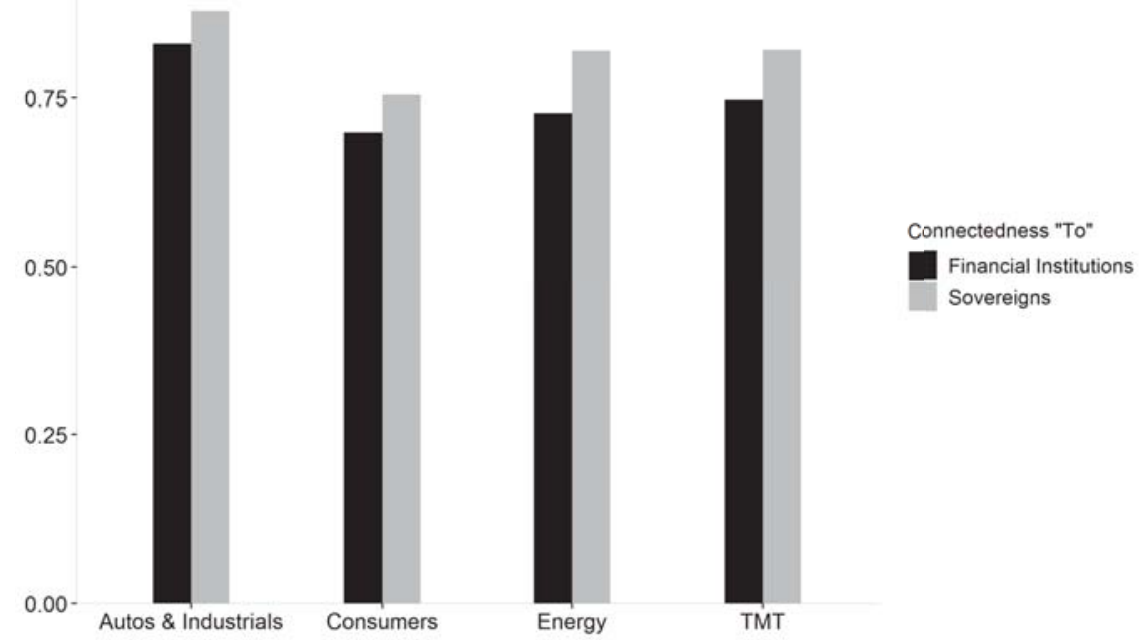

Note: The figure shows the share of Granger-causality linkages between sectors, i.e. it presents the share of non-zero links relative to the total number of possible links across sectors.

\section{Robustness checks results}

Figure OA.5: Network with forecast horizon $h=5$

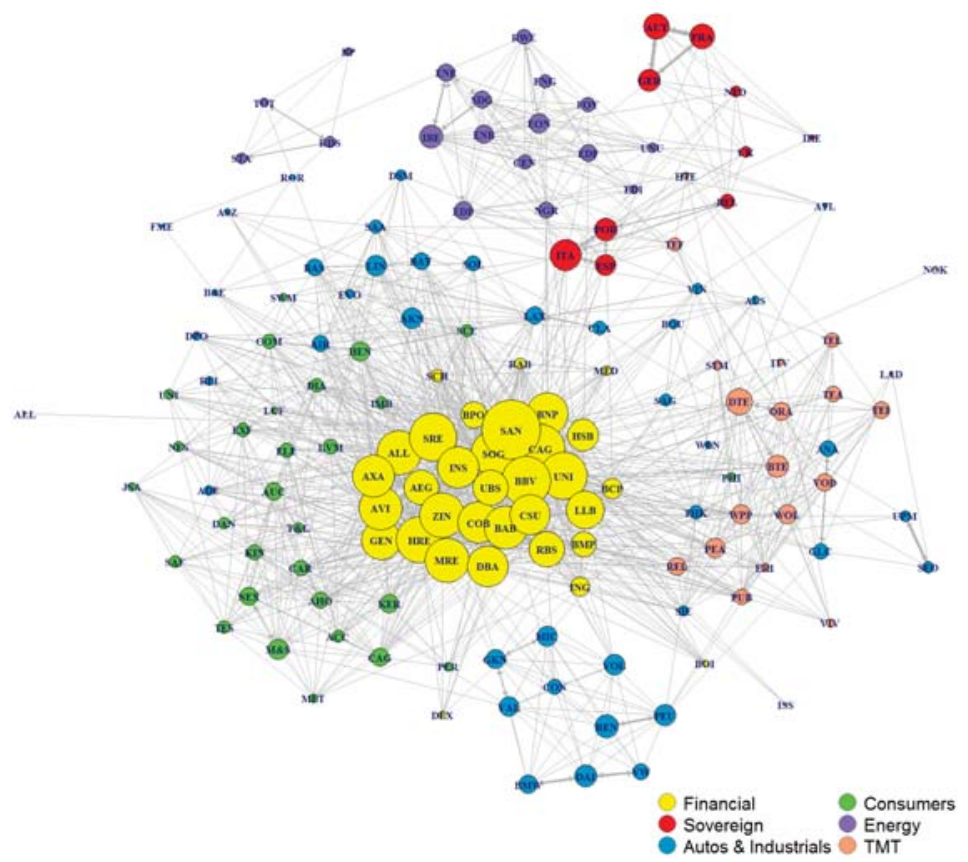


Figure OA.6: Network with forecast horizon $h=15$

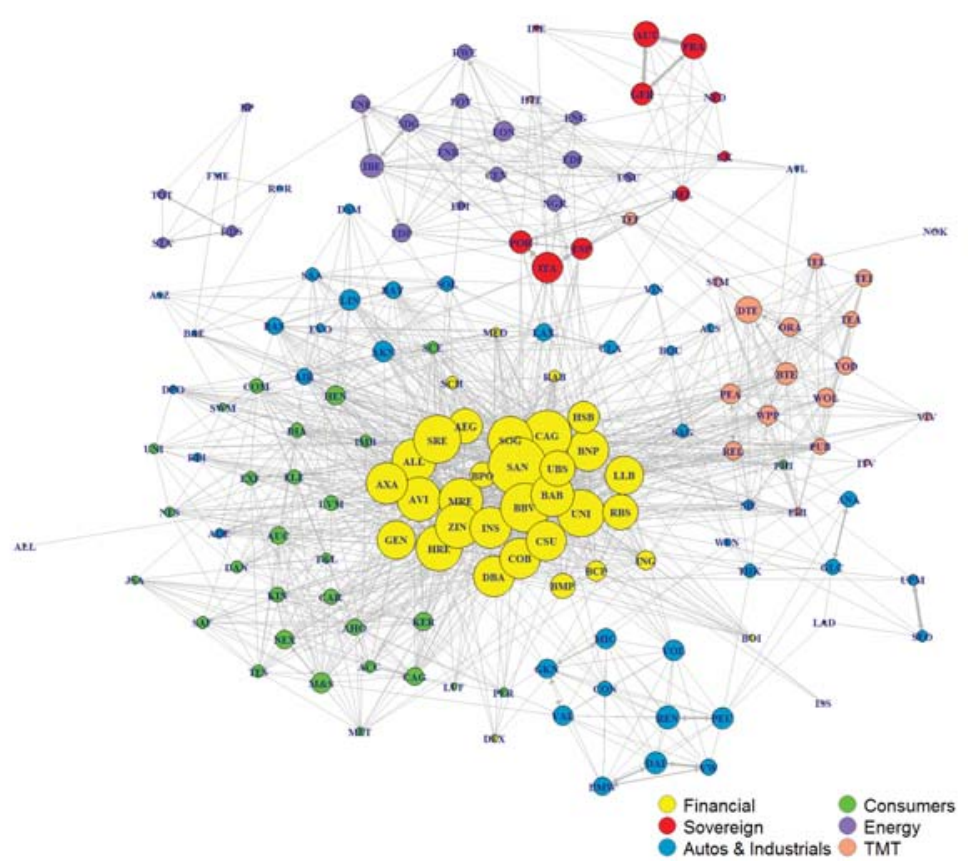

Figure OA.7: Network with forecast horizon $h=20$

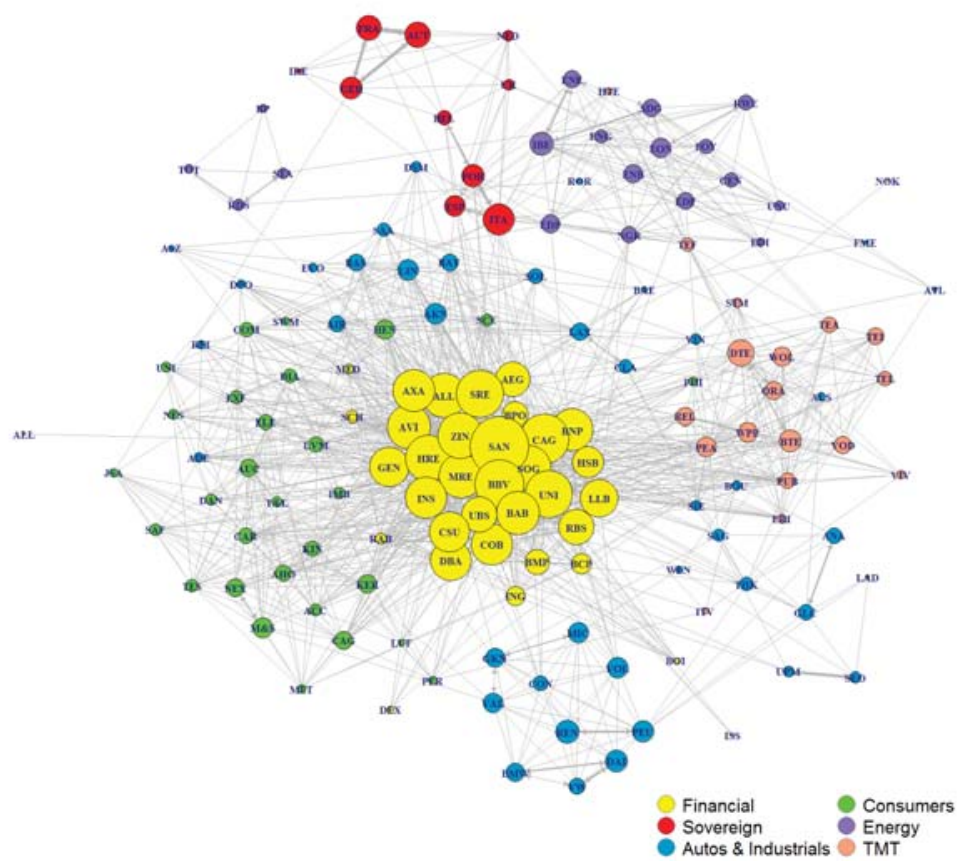


Figure OA.8: Network based on 2-factor model

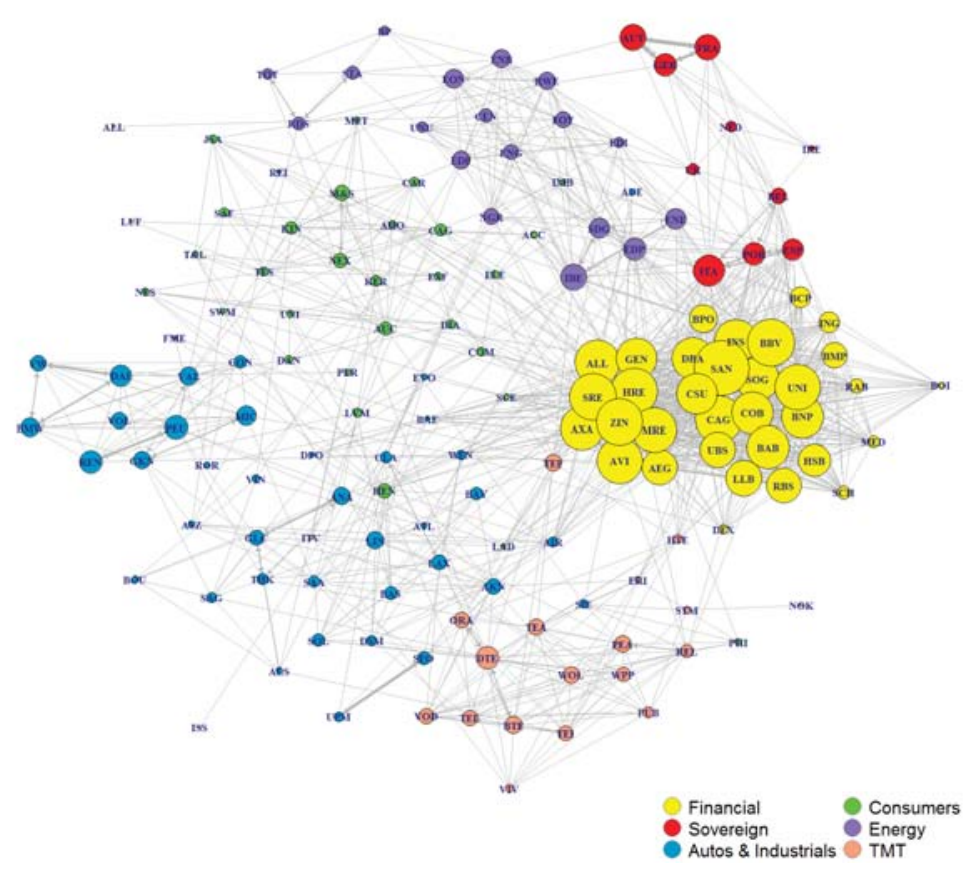

Table OA.2: Rank correlation coefficients between baseline model (1 factor, 10 days forecast horizon) and alternative specifications

(a) Financial $\rightarrow$ Non-Financial

\begin{tabular}{|c|c|c|}
\hline & Ranking of Senders & Ranking of Receivers \\
\hline \multicolumn{3}{|l|}{ Forecast horizon } \\
\hline 5 days & $0.997^{* * *}$ & $0.997^{* * *}$ \\
\hline 15 days & $0.981^{* * *}$ & $0.996^{* * * *}$ \\
\hline 20 days & $0.997^{* * *}$ & $0.997^{* * *}$ \\
\hline$\underline{2 \text { common factors }}$ & $0.812^{* * *}$ & $0.439^{* * *}$ \\
\hline \multicolumn{3}{|c|}{ (b) Sovereign $\rightarrow$ Non-Financial } \\
\hline & Ranking of Senders & Ranking of Receivers \\
\hline \multicolumn{3}{|l|}{ Forecast horizon } \\
\hline 5 days & $0.987^{* * *}$ & $0.989^{* * *}$ \\
\hline 15 days & $1.000^{* * *}$ & $0.993^{* * *}$ \\
\hline 20 days & $0.987^{* * *}$ & $0.989^{* * * *}$ \\
\hline 2 common factors & $0.988^{* * *}$ & $0.809^{* * *}$ \\
\hline
\end{tabular}


Figure OA.9: Dynamic system-wide connectedness for different window sizes

(a) 150 days

100 -

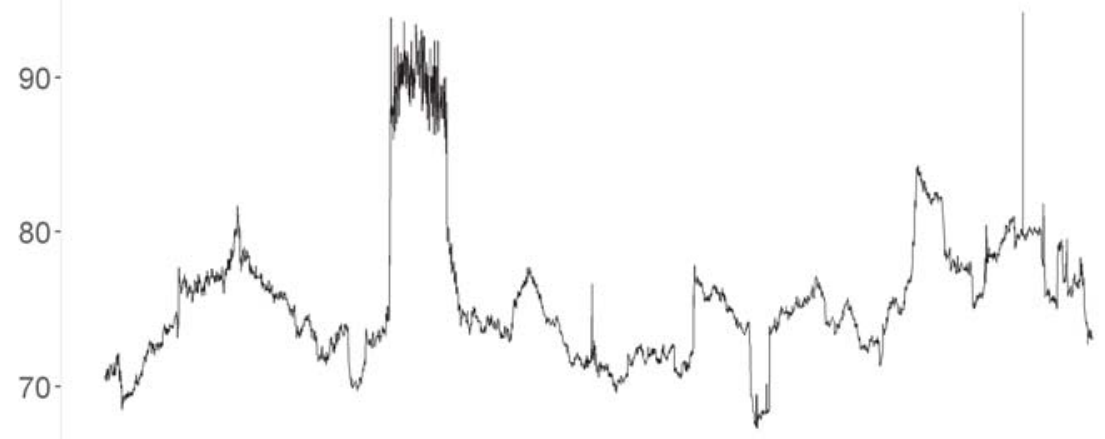

$60-$

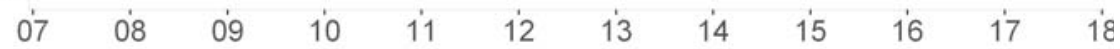

(b) 200 days

100

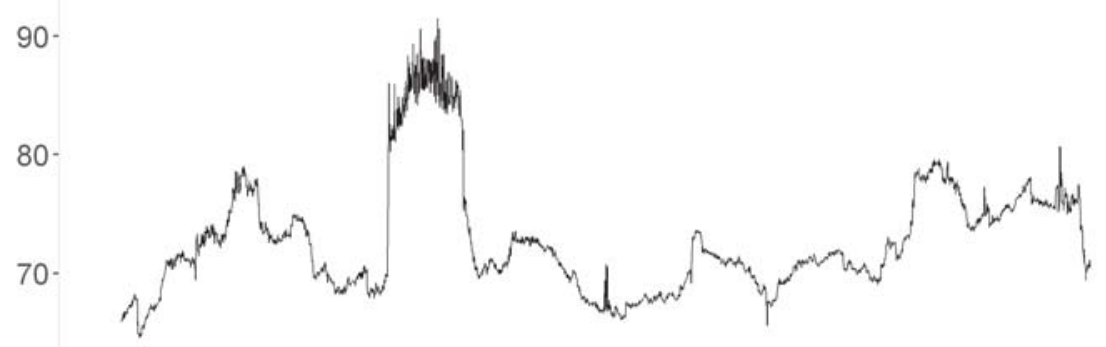

60 -

$\begin{array}{llllllllllll}07 & 08 & 09 & 10 & 11 & 12 & 13 & 14 & 15 & 16 & 17 & 18\end{array}$

(c) 250 days

100 -

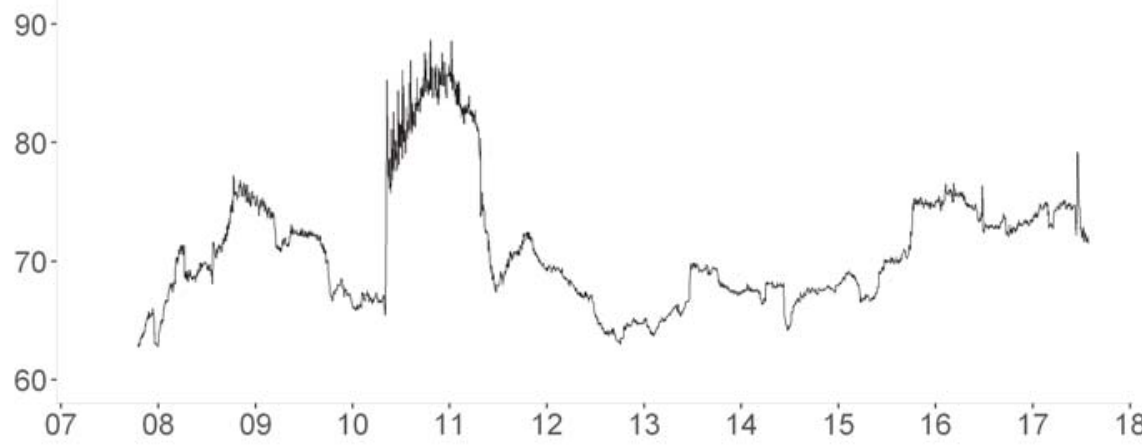

